\title{
Protesta popular en San Miguel: repensar la ola de movilización social de 1927- 1932 desde el oriente salvadoreño*
}

\section{Resumen}

En este artículo se exploran las manifestaciones de protesta popular en San Miguel, El Salvador, dentro de la más amplia ola de movilización que recorrió al país entre 1927 y 1932. A diferencia de los lugares comunes de la historiografía salvadoreña, la región oriental no fue ajena a los procesos de organización, conflicto, radicalización ideológica y protesta que caracterizaron al centro-occidente. Los movimientos reivindicativos y la gran revuelta de octubre de 1930 en San Miguel, la ciudad más importante del oriente salvadoreño, permiten conocer en profundidad una cultura de la protesta popular dentro de un escenario de movilización signado simultáneamente por distintas escalas espaciales. En primer lugar, se abordan las condiciones que hicieron posibles estas formas de movilización; en segundo lugar, se analizan los rasgos de las principales expresiones de esta protesta popular, enfocándose en los sujetos, las formas de acción, los adversarios, los discursos y los objetivos desplegados; y en tercer lugar, se elabora un análisis del conjunto de estas movilizaciones. Como veremos, en el marco de la conjunción específica de condiciones estructurales y coyunturales, la protesta popular de San Miguel se distinguió por la movilización protagónica de artesanos-obreros y vendedoras de los mercados, quienes desplegaron como repertorios de acción una hibridación de formas tradicionales y modernas, siguiendo su propio camino hacia un proceso de radicalización.

Palabras clave: El Salvador, conflicto social, movimientos sociales, protesta, radicalismo.

Referencia para citar este artículo: Referencia para citar este artículo: GONZÁLEZ MÁRQUEZ, Luis Rubén (2015). "Protesta popular en San Miguel: repensar la ola de movilización social de 1927-1932 desde el oriente salvadoreño”. En Anuario de Historia Regional y de las Fronteras. 20 (2). pp. 17-46.

Luis Rubén González Márquez: Estudiante de Maestría en Sociología de la Facultad Latinoamericana de Ciencias Sociales (FLACSO), sede Ecuador. Licenciado en Historia por la Universidad de El Salvador. Correo electrónico: 1rsk8@hotmail.com.

* Una versión preliminar de este artículo se expuso como ponencia en el XII Congreso Centroamericano de Historia, San Salvador, 15-18 de julio de 2014, en la mesa temática "Rebeliones y movilización social". Agradecimientos a los asistentes y coordinadores por sus comentarios en aquella ocasión. 


\title{
Popular protest in San Miguel: reconsidering the 1927- 1932 social mobilization wave from the salvadoran east
}

\begin{abstract}
This article delves into the popular protests in San Miguel within the widest mobilization wave that went all over El Salvador between 1927 and 1932. Different from the common places in the Salvadoran historiography, the eastern region was not unconnected to the organization, conflict, ideological radicalism and protest features of the west-central region. In any case, they found different ways and means for expression, rooted in the particular regional and local conditions. The types of redeeming movements and the big riot of October 1930, in the most important city in the Salvadoran east, San Miguel, allow a deep understanding of a culture of popular protest within a mobilization scenario simultaneously marked by different spatial scales. Thus, firstly, the conditions that made these mobilization forms in San Miguel are addressed; secondly, the features of the main expressions of that popular protest, focusing on the subjects, the forms of action, the adversaries, the speeches and the displayed objectives and, thirdly, an overall analysis of this mobilizations is performed. As we will see, within the framework of the specific conjunction of structural and situational conditions, the popular protest of San Miguel stood out because of the emergence of the leading role of craftsmenworkers and female traders of the markets, who deployed a hybridization of traditional and modern forms as their action repertoires and, by following their own way, a growing radicalism process.
\end{abstract}

Keywords: El Salvador, social conflict, social movements, protest, radicalism.

\section{Protesta popular em São Miguel: repensar a onda de mobilização social de 1927- 1932 desde o oriente salvadorenho}

\section{Resumo}

Neste artigo, exploram-se as manifestações de protesto popular em São Miguel dentro da mais ampla onda de mobilização que aconteceu no El Salvador entre 1927 e 1932. A diferença dos lugares comuns da historiografia salvadorenha, a região oriental não foi alheia aos processos de organização, conflito, radicalização ideológica e protesto que caracterizaram o centro-ocidente. Em todo caso, encontraram causes e formas de expressão diferentes, insertos nas particulares condições regionais e locais. Os tipos de movimentos reivindicativos e a grande revolta de outubro de 1930 na cidade mais importante do oriente salvadorenho, São Miguel, permitem conhecer amplamente uma cultura do protesto popular dentro de um cenário de mobilização designado simultaneamente por diferentes escalas espaciais. Assim, em primeiro lugar são abordadas as condições que fizeram possível estas formas de mobilização em São Miguel; em segundo lugar, analisam-se os rasgos das principais expressões deste protesto popular, focando nos sujeitos, as formas de ação, os adversários, os discursos e os objetivos desdobrados, e em terceiro lugar, é elaborado um análise de conjunto destas mobilizações. Como veremos, no marco da conjunção específica de condições estruturais e conjunturais, a protesta popular de São Miguel distinguiu-se pela ativação protagonizada por artesãos-pedreiros e vendedoras dos mercados, que desdobraram como repertórios de ação uma hibridação de formas tradicionais e modernas, e seguindo seu próprio caminho, um processo de radicalização crescente.

Palavras-chave: El Salvador, o conflito social, movimentos sociais, protestos, radicalismo. 


\section{Introducción}

Nuestro punto de partida en el presente artículo es la siguiente pregunta: ¿cuáles fueron las expresiones de protesta popular en la localidad de San Miguel, ubicada en la región del oriente salvadoreño, durante el ciclo de movilización social 1927-1932? En otras palabras, nuestro propósito es analizar cómo San Miguel nos puede servir de "espacio de experimentación historiográfica" para replantear, desde las múltiples escalas en las que se inserta, lo que el sociólogo Paul Almeida caracterizó como la primera "ola de protesta popular" en El Salvador del siglo XX1.

Hasta ahora, ante el interés despertado por la rebelión de enero de 1932 en el occidente salvadoreño, esta ola de movilización ha sido abordada en una importante cantidad de estudios en el país y en el extranjero que nos permiten conocer con relativa profundidad el contexto político y económico, las estructuras organizativas básicas y algunos episodios de protesta que la conformaron. A pesar de sus posibilidades, estas obras presentan limitantes, tales como: análisis unívocamente orientados a la mencionada rebelión, escasez de estudios micro (locales y regionales), excesiva concentración en la región occidental disimulada detrás de relatos nacionales y, a veces, un énfasis injustificado en los teatros de acción y sujetos rurales ${ }^{2}$. Al profundizar en el conocimiento de las movilizaciones sociales desde un enfoque micro, en el frecuentemente olvidado espacio de la región oriental, podremos obtener una mirada más amplia de este ciclo de protesta y ulteriormente plantear análisis comparativos que permitan una comprensión más completa del mismo ${ }^{3}$.

Para comprender la protesta popular en San Miguel entre 1927-1932 han sido cruciales los análisis de los movimientos sociales en contextos de incipiente modernización de las sociedades tradicionales, formulados por los llamados "marxistas británicos"4, y los

\footnotetext{
${ }_{1}^{1}$ ALMEDIA, Paul, Olas de movilización popular: movimientos sociales en El Salvador, 1925-2010, San Salvador, UCA Editores, 2011, pp. 45-111; GONZALEZ, Luis, AGUIRRE ROJAS, Carlos Antonio, ASSAD, Carlos Martínez, "Mesa redonda: microhistoria italiana, microhistoria mexicana e historia local", en Relaciones, Vol. XXVI, Michoacán, COLMICH, 2005, pp. 193-224.

${ }^{2}$ Para una exploración de la historiografía sobre movimientos sociales de El Salvador: LÓPEZ BERNAL, Carlos Gregorio, "Historiografía y movimientos sociales en El Salvador (1811-1932): un balance preliminar”, en Revista de historia, No. 67, San José, Universidad de Costa Rica, junio de 2013, pp. 89-119.

${ }^{3}$ Sobre esto, GOULD, Jeffrey y LAURIA, Aldo, 1932: rebelión en la oscuridad, San Salvador: Ediciones Museo de la Palabra y la Imagen, 2008; LÓPEZ BERNAL, Carlos Gregorio, "El levantamiento indígena de 1846 en Santiago Nonualco. Conflictos locales, etnicidad y lucha de facciones en el Salvador", en Revista de historia, No. 42, San José, Universidad de Costa Rica, 2000, pp. 9-41; LAURIA, Aldo, "Holding the City Hostage: Popular Sectors and Elites in San Miguel, El Salvador, 1875”, en The Americas, Vol. 68, No 1, julio de 2011, pp. 63-95. Desde la brecha abierta por estos trabajos elaboramos un estudio a profundidad sobre la revuelta de octubre de 1930 en San Miguel: GONZÁLEZ MÁRQUEZ, Luis Rubén, "Han ocurrido bochinches. La revuelta de San Miguel en octubre de 1930: movilización social y violencia colectiva de la muchedumbre citadina", en BERGMANN, Adrián y MELÉNDEZ, Óscar (Eds.), La violencia en los tiempos de paz: vida cotidiana y políticas públicas en El Salvador, San Salvador, DNI, 2015 (En prensa).

4 THOMPSON, Edward, "La economía moral de la multitud en la Inglaterra del siglo XVIII", en THOMPSON, E.P., Tradición, revuelta y conciencia de clase, Barcelona: Crítica, 1984, pp. 62-133; RUDÉ, George, "Los movimientos de masas en el período preindustrial", en RUDÉ, George, Protesta popular y revolución en el siglo XVIII, Barcelona, Editorial Ariel, 1978, pp. 17-33; RUDÉ, George, Revuelta popular y conciencia de clase, Barcelona, Critica, 1981; HOBSBAWM, Eric, Rebeldes primitivos. Estudio sobre las
} 
análisis de una reciente historia social latinoamericana que ha intentado problematizar y ubicar las reflexiones de los primeros en la realidad del subcontinente ${ }^{5}$.

Mapa 1. Región del Oriente Salvadoreño y Región de las Segovias nicaragüenses en Centroamérica

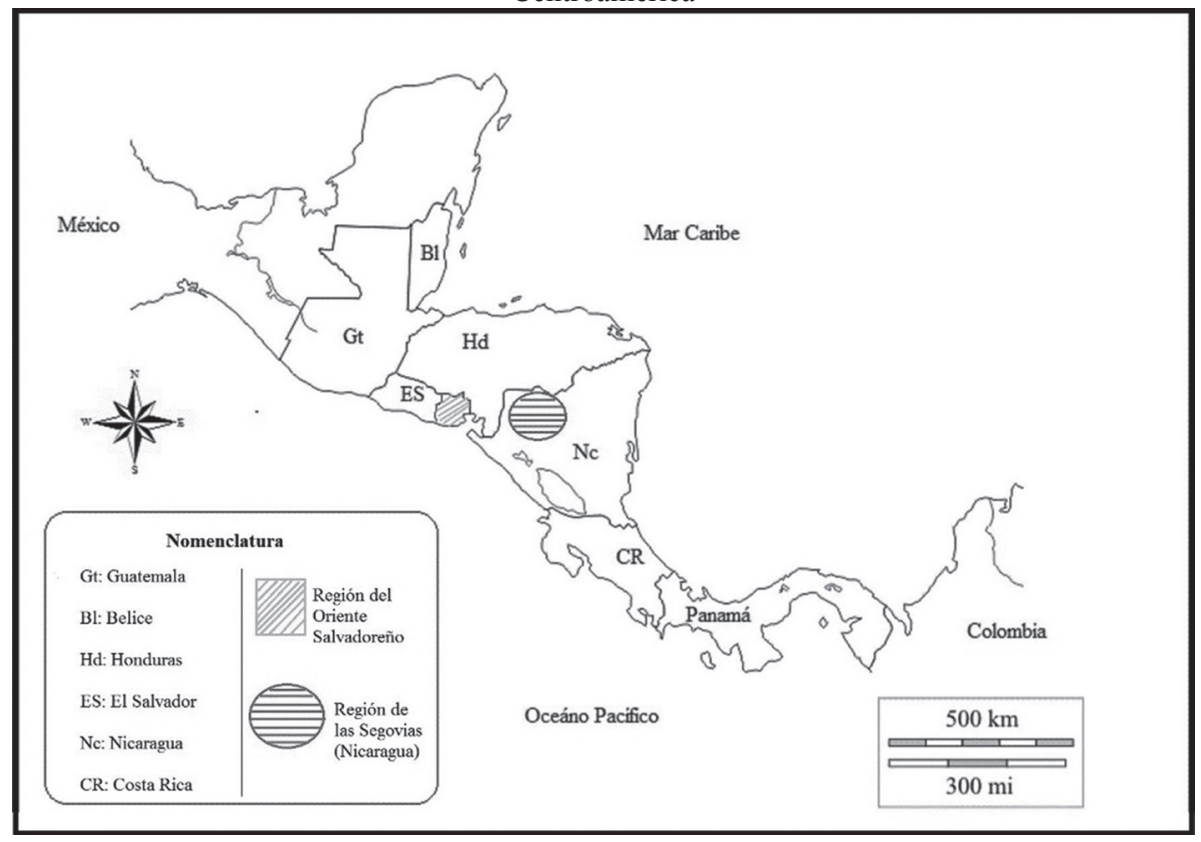

Fuente: elaboración propia

Es preciso tener en cuenta que a raíz de las dificultades de acceso a fuentes oficiales en la región del oriente salvadoreño (Ver Mapa 1$)^{6}$, por su dispersión, fue fundamental

formas arcaicas de los movimientos sociales en los siglos XIX y XX, Barcelona, Ariel, 1983.

${ }^{5}$ GOICOVIC DONOSO, Igor, "Consideraciones teóricas sobre la violencia social en Chile (1850-1930)", en Última década, No. 21, Santiago de Chile, diciembre de 2004, pp. 121-145; ROMERO, Luis Alberto, "Los sectores populares urbanos como sujetos históricos", en Última década, No. 7, Santiago de Chile, agosto de 1997, pp. 9-3; POLO BUITRAGO, Sandra Milena, "Movilización popular en Bogotá en la segunda mitad del siglo XIX: el caso del Motín del Pan del 23 de enero de 1875", en Historia Crítica, No. 35, Bogotá, Universidad de los Andes, junio de 2008, pp. 16-33.

${ }^{6}$ Estas dificultades son evidentes en un novedoso e inédito estudio sobre la formación del oriente salvadoreño. Agradecemos a su autora por permitirnos acceder a él y fomentar nuestro interés en la historia de la región: AVENDAÑO, Xiomara, "La formación histórica del oriente salvadoreño: territorio, división político administrativa e identidad (inédito)", Centro de Investigaciones Científicas-Universidad de El Salvador, marzo de 2014. A pesar de centrarnos en una localidad es crucial la referencia a la región, a la cual, siguiendo a Carlos Hernández, concebimos "más que como un campo de estudio [...] como una opción metodológica eventualmente útil para el planteamiento, análisis y resolución de determinadas problemáticas". HERNÁNDEZ, Carlos, "Ampliando perspectivas, reduciendo escalas: el mundo del trabajo, la movilización y la protesta social en perspectiva regional comparada”, en CHEN MOK, Susana, MALAVASSI AGUILAR, Ana Paulina y VIALES, Ronny (Eds.), Teoría y métodos de los estudios regionales y locales, San José, Sistema Editorial de Difusión Científica de la Investigación-Universidad de Costa Rica, 2008, p. 168. 
la información de la prensa escrita, específicamente la prensa local de la ciudad, un tipo de periodismo autodefinido como regional, en especial los periódicos La Nación y el Diario de Oriente.

Siguiendo estas consideraciones, en una primera parte, nos concentramos en las condiciones que hicieron posible la ola de movilización de 1927-1932 en San Miguel. En la segunda parte, analizamos las expresiones más notorias de esta protesta popular en la localidad. Por último, elaboramos un análisis del conjunto de las movilizaciones.

Mapa 2. Ubicación del municipio y núcleo urbano de San Miguel en El Salvador

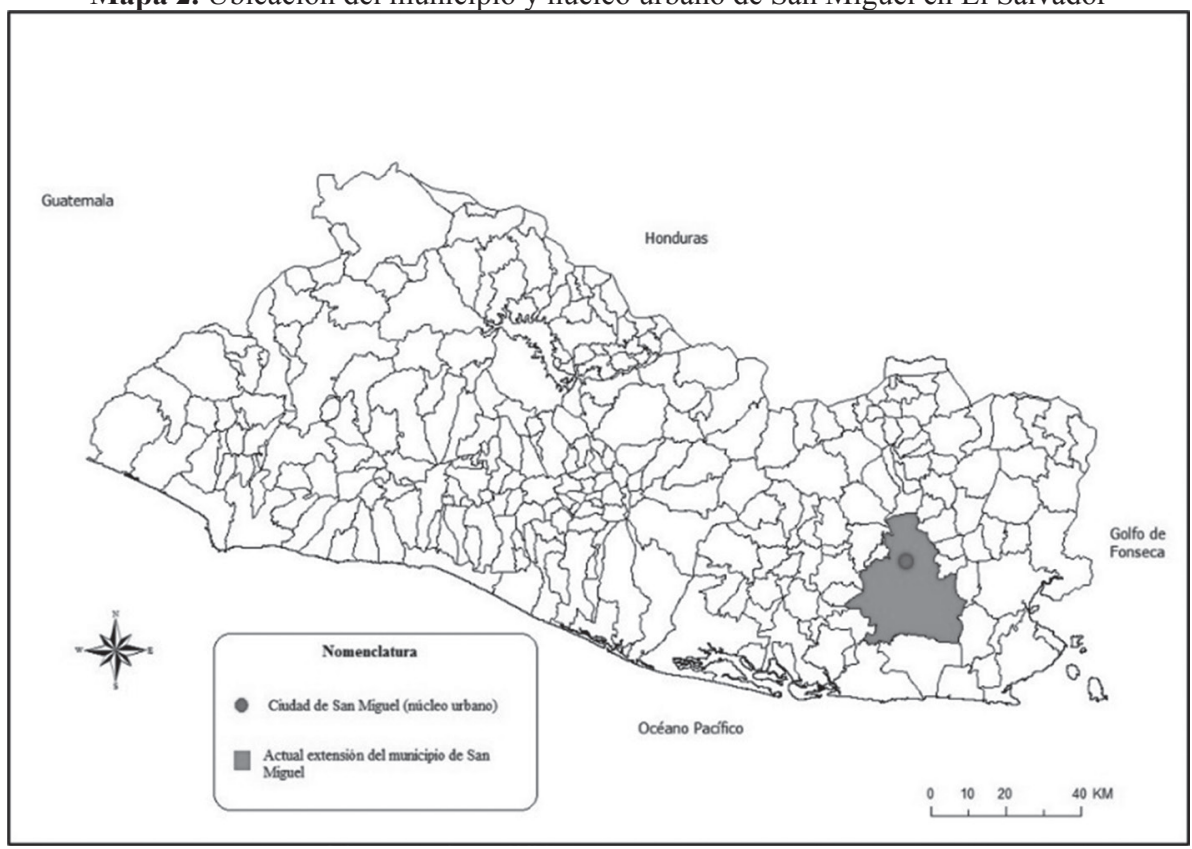

Fuente: elaboración propia

\section{Crisis económica, infraestructura organizativa y memoria plebeya en San Miguel}

Hacia finales de la década de los veintes, San Miguel era la ciudad más importante de la amplia región oriental (Mapa 2) y la tercera en todo El Salvador. Al igual que la mayor parte de las grandes concentraciones poblacionales del país, está ubicada en los valles intermontanos de la cadena volcánica, "en un hermoso y extenso valle al NE. (Noreste) del volcán" Chaparrastique o de San Miguel"

En los casi cincuenta años entre 1870 y 1932, San Miguel fue signado por los efectos particulares del entrecruce de fenómenos y procesos sociales en distintas escalas y direcciones. Por una parte, en la esfera socioeconómica, el descenso del añil y el

${ }^{7}$ BARBERENA, Santiago, Monografías departamentales, San Salvador, DPI, 1998, p. 495. 
ascenso del café a nivel nacional plantearon un reto para la economía de la ciudad - específicamente para las elites- acerca de cómo integrarse al mercado mundial al margen de aquél cultivo y sus actividades comerciales asociadas ${ }^{8}$. Como había pocas zonas con potencial cafetalero en la región, con excepción de la sierra TecapaChinameca que estaba dominada por una nueva elite regional del departamento de Usulután ${ }^{9}$, esos intentos se enfocaron en otros productos, todos problemáticos, como el algodón, la minería y principalmente, por sus bajas necesidades de inversión y sobre todo ajustarse a la estructura social rural de la zona, el henequén ${ }^{10}$. Otra vía de contención fue una renovada economía campesina de trueque de productos de consumo básico conectada con el suroriente hondureño y el occidente de Nicaragua ${ }^{11}$. Además, continuaba siendo el punto nodal, aunque ya no único, del comercio internacional que transitaba por tierra y por el Puerto de la Unión, lo cual permitía la vigencia de la larga tradición comercial migueleña ${ }^{12}$.

Como consecuencia de estas transformaciones, se había reconfigurado tanto la estructura territorial como la demográfica, la configuración étnica y social del municipio de San Miguel. En el primer caso, como es evidente en el Mapa 2, la ciudad se perfiló como un núcleo urbano rodeado de un extenso hinterland rural. Según el censo de 1930, su población presentaba una relativa alta concentración demográfica y urbana ${ }^{13}$. En segundo lugar, respecto a la etnicidad, como demuestra Avendaño, la ladinización y mestizaje de la población, con una notable descendencia de mulatos y afrodescendientes, fue un proceso particularmente intenso en casi toda la zona oriental -salvo el norte Morazán- y altamente consolidado entre los sectores populares migueleños desde finales del siglo XIX, en contraste con el centro-occidente del país ${ }^{14}$. Las elites locales migueleñas presentan una composición diferente, fundamentalmente de origen español, ya que desde finales del siglo XIX se les habían incorporado inmigrantes del Viejo Mundo, con el reforzamiento concomitante de su identidad como "blancas"15.

\footnotetext{
${ }^{8}$ FERNÁNDEZ, José Antonio, Pintando el mundo de azul: el auge añilero y el mercado centroamericano, 1750-1810, San Salvador, DPI, 2003, p. 123.

${ }^{9}$ CAMPOS LARA, Óscar, "Cafetaleros de Santiago de María: la formación de un poder microregional en la Sierra Tecapa de Usulután, 1874-1917”, Tesis de licenciatura, Universidad Tecnológica de El Salvador, 2007.

${ }^{10}$ WILSON, Evertt Alan, La crisis de la integración nacional en El Salvador: 1919-1935, San Salvador, DPI, 2004, pp. 72-74; BERMÚDEZ, Alejandro, El Salvador al vuelo, San Salvador, s.e., 1917, p. 99; GUIDOS VÉJAR, Rafael, El ascenso del militarismo en El Salvador, San José, EDUCA, 1982, p. 83; LINDO-FUENTES, Héctor, La economía de El Salvador en el siglo XIX, San Salvador, DPI, 2002, pp. 143172; LAURIA, Aldo, Una República agraria: los campesinos en la economía y la política de El Salvador en el siglo XIX, San Salvador, DPI, 2003, p. 56.

${ }^{11}$ LAURIA, Aldo, "Holding the City Hostage...", Op. cit., p. 76.

${ }^{12}$ FERNÁNDEZ, José Antonio, Op. cit., pp. 200-201.

${ }^{13}$ En total presentaba 39989 habitantes, es decir, el 31,6\% de toda la población del departamento de San Miguel, una mayoría de los cuales el 57,7\% eran clasificados (no sabemos bajo qué criterio) como "rurales", mientras los habitantes clasificados como "urbanos" representaban el 43,3\%. MEJÍA PÉREZ, José, Censo del $1^{\circ}$ de mayo de 1930, San Salvador, Dirección General de Estadística, 1939, pp. 7-378.

${ }^{14}$ AVENDAÑO, Xiomara, Op. cit., pp. 34-40.

${ }^{15}$ Esto no es ageno al resto de elites del país, aunque la procedencia de los principales grupos presentaba variaciones. Según Ginny Charlaix, en San Miguel estos eran los suizos, italianos y palestinos. CHARLAIX
} 
A pesar de la carencia de fuentes y estudios ha sido posible encontrar algunas indicaciones de la estructuración social de San Miguel de principios del siglo XX. Por el lado de los estratos superiores, el proceso de concentración económica en una oligarquía pequeña, ubicada en el comercio internacional, el financiamiento y el procesamiento de la agricultura de exportación, cristalizó en el oriente salvadoreño en un personaje: Mauricio Meardi. Este era un inmigrante italiano cuya fortuna creció por medio del cultivo de café en Usulután, al occidente el volcán Chaparrastique. Con el poder económico adquirido, él y otros cafetaleros se incorporaron a la elite migueleña, dadas las oportunidades de expansión y diversificación de actividades que ofrecía. No obstante, gracias a un proceso todavía por estudiar, Meardi logró ser el que mejor aprovechó la situación. Él, junto a su red de aliados, logró dominar la elite de San Miguel e incluso de toda la región oriental ${ }^{16}$.

Subordinado a este grupo se encontraba el resto de elites locales (comerciantes, productores agrarios a gran escala y algunos profesionales), tanto familias tradicionales como inmigrantes. En los estratos medios y bajos destaca el peso de los comerciantes a mediana escala y los vendedores, entre ellos las vendedoras de los mercados ${ }^{17}$. En el caso de los primeros, se agregaban a los profesionales, empleados públicos, productores medianos, periodistas, artesanos propietarios, entre otros, que configuraban la clase media salvadoreña de la época ${ }^{18}$. En los estratos populares, encontramos un contingente heterogéneo de operarios artesanales, obreros, pequeños propietarios agrícolas, apareceros, jornaleros, etcétera.

Es en este panorama económico-social, local y regional, operaron los efectos de la crisis económica mundial de 1929, percibidos desde 1927 y en dimensiones agudas en $1932^{19}$. Esta crisis intensa se articuló con una más crónica de redefinición posterior a la del añil, descrita anteriormente. Al considerar la presión sobre la demanda, los salarios en la agricultura de exportación, el aumento y repentino descenso de precios de los granos básicos y la reducción de las finanzas estatale ${ }^{20}$ podemos introducir como hipótesis que esta depresión clausuró por un momento la búsqueda de alternativas de integración al mercado mundial de la elite migueleña. Entretanto, los efectos más sentidos se centraron, en primer lugar, en el agudo ascenso y descenso súbito de la demanda, lo que incidió en los precios de los productos del pequeño campesinado, y en segundo lugar, en la reducción del financiamiento, cierre y ejecución de hipotecas inmobiliarias y bienes de los agricultores y los artesanos citadinos. Articulada a la

DE MUSCHENBORN, Ginny, San Miguel: historia, tradiciones, Carnaval : una visión de San Miguel desde la prehistoria al Carnaval, San Miguel, [s.n.], 2010, p. 64.

${ }^{16}$ GONZÁLEZ MÁRQUEZ, Luis Rubén, "Han ocurrido bochinches...”, Op. cit., p. 8.

${ }^{17}$ Lo indican impresiones publicadas en la prensa, por ejemplo, en 1929 una carta dice que "el pequeño comercio [...] es el verdadero pueblo quien lo ejerce". CARÍAS, J.M. et al, "Memorial de los comerciantes, agricultores, artesanos y vecinos de esta ciudad: a la Corporación Municipal sobre la nueva Tarifa de Arbitrios Municipales", en La Nación (LN), San Miguel, 14 de Junio de 1929, p. 1.

${ }^{18}$ WILSON, Evertt Alan, Op. cit., pp. 129-162.

${ }^{19}$ BULMER-THOMAS, Víctor, La economía politica de Centroamérica desde 1920, San José, Banco Centroamericano de Integración económica-EDUCA, 1989, p. 61.

${ }^{20}$ Ibid., pp. 69-73. 
reducción de capacidad de consumo, se puede registrar un aumento en los precios de los bienes de consumo básicos y por consecuencia una fuerte reducción del comercio mediano y pequeño, vital para la ciudad. Finalmente, este panorama redundó en un aumento de demandas sobre el Estado y en presiones a las finanzas públicas. Así parece expresarlo la siguiente descripción periodística de junio de 1929:

La situación económica en general no es bonancible. Díganlo si no los hechos de que los Bancos han retirado sus sucursales, el alto comercio en gran parte se ha trasladado a San Salvador y el proletariado emigra en grandes proporciones hacia la Costa Norte de Honduras ¿No forman estos hechos un índice de nuestra mala situación económica??

Por otra parte, desde principios del siglo XX se había cimentado toda una infraestructura organizativa $^{22}$ de diversos grupos sociales de San Miguel, como en el resto del país, que hacía posible articular intereses colectivos y canalizar sus demandas ante otros actores sociopolíticos en la esfera pública, esto permitía la morigeración de las contiendas por el poder a través de incipientes prácticas electorales, la politización creciente de los sectores populares y un mayor ejercicio de la libertad de asociación ${ }^{23}$. La punta de lanza de esta infraestructura la constituían las sociabilidades formales de los artesanos-obreros: asociaciones, uniones, sociedades, clubes deportivos, asociaciones caritativas y tardíamente asociaciones de resistencia y sindicatos, que se expandieron a lo largo y ancho de El Salvador desde finales del siglo XIX ${ }^{24}$.

En la ciudad de San Miguel nos encontramos que en el segundo lustro de la década de los veintes había algunas organizaciones artesanales-obreras activas. La más importante, sin duda, era la Unión de Obreros de San Miguel, una organización de base nacida entre finales de 1922 y mayo de 1923, de la fusión de organizaciones precedentes, la Sociedad de Artesanos y la Sociedad "Luis Alonso Barahona". La Unión de Obreros legó de ambas organizaciones un contingente de activos líderes trabajadores de gremios y "factores de comercio" como Carlos Rosales, Heriberto Romero, Antonio Mayorga, Fermín Urquilla, Leopoldo Chavarría o José María Molina. Igualmente, integró a sus redes a mujeres líderes, la mayoría profesoras y otras provenientes de los sectores populares urbanos, además trazó alianzas con influyentes miembros de los sectores medios ${ }^{25}$. Adicionalmente, podemos referir que la Unión de Obreros de San

\footnotetext{
${ }^{21}$ COREDERO ROSALES, Rafael et al, "Los profesionales migueleños se declaran contra la Tarifa de Arbitrios Municipales", en $L N, 20$ de junio de 1929, p. 1.

${ }^{22}$ Estas son "estructuras organizacionales duraderas", que incluyen "organizaciones civiles", "instituciones sociales" e "individuos con habilidades organizacionales". ALMEIDA, Paul, Op. cit., pp. 16-17.

${ }_{23}$ ALVARENGA, Patricia, Cultura y ética de la violencia: El Salvador, 1880-1932, San José, EDUCA, 1996, pp. 219-223.

${ }^{24}$ GONZÁLEZ MÁRQUEZ, Luis Rubén, "Sociabilidad y organizaciones artesanales-obreras. La Sociedad de Artesanos El Porvenir de Santa Tecla, 1902-1932”, Tesis de licenciatura, Universidad de El Salvador, 2012, pp. 113-129 y 181-189; ACUÑA ORTEGA, Víctor Hugo, "The Formation of the Urban Middle Sectors in El Salvador, 1911-1944”, en BINFORD, Leigh, LAURIA, Aldo (Ed.), Landscape of Struggle: Politics, Society and Community in El Salvador, Pittsburgh, University of Pittsburgh Press, 2004, pp. 39-49.

${ }^{25}$ Archivo General de la Nación (AGN), Fondo Ministerio de Gobernación-del Interior, Libros de estatutos y reglamentos, Libro de 1923, "Estatutos de la Unión de Obreros de San Miguel”, ff. 115-116.
} 
Miguel poseía algunos vínculos con las federaciones obreras establecidas en el país, como la Sociedad de Obreros de El Salvador Confederada y con la Unión de Obreros Salvadoreños ${ }^{26}$, sumado a esto había asumido como propio, dentro de su estructura interna, el proyecto de una Universidad Popular de San Miguel ${ }^{27}$.

Otra importante asociación artesanal de San Miguel era la Sociedad Esfuerzo y Cultura. Ciertamente sus capacidades de presión eran menores tanto por el tamaño de su membresía y estructura organizativa, como por la falta de local propio, aun así tenía un importante peso en la opinión pública gracias a su alianza con el periódico $L a$ Nación ${ }^{28}$ y con la Federación Regional de Trabajadores Salvadoreños (FRTS). Entre sus líderes se encontraban Heriberto Romero, Leopoldo Chavarría, Julián Núñez, Víctor Mendoza, Román Cortez, Jesús Urquilla. De hecho, la FRTS intentó usar a esta sociedad como punta de lanza para su expansión hacia el oriente salvadoreño. Aunque a nivel orgánico fue un intento fallido, lograron dictar conferencias en San Miguel "[...] sobre orientación sindical y organización eficiente para la preparación de las clases laborantes en la lucha" ${ }^{\prime 29}$.

El poder local y regional de estas asociaciones obreras se vio fortalecido con el ascenso a la presidencia de Pío Romero Bosque en 1927 (hasta 1931), dado que con él se inicia una política institucional que las incluía a ellas y a los trabajadores urbanos como actores políticos clave, bajo la consigna de la colaboración del capital y el trabajo, esto se logró mediante la creación de un Ministerio de Trabajo, un nuevo registro de asociaciones y la creación de Juntas de Conciliación departamentales entre trabajadores y patronos ${ }^{30}$. La Junta de Conciliación del departamento de San Miguel ubicó en una nueva escala de poder a los liderazgos de las asociaciones artesanalesobreras de la ciudad de San Miguel ${ }^{31}$, no todos trabajadores de gremios.

\footnotetext{
${ }^{26}$ AGN, Fondo Ministerio de Gobernación-del Interior, Libros de estatutos y reglamentos, Libro de 1923, "Estatutos de la Unión de Obreros de San Miguel”, f. 116.

${ }^{27}$ ANÓNIMO, "San Miguel por dentro: invitación”, en Diario de Oriente (Dor), San Miguel, 29 de marzo de 1927, p. 6. Las universidades populares que surgieron en América Latina durante este período estaban conectadas entre sí y tenían un origen común ligado al aprismo de Haya de la Torre, aunque el peso que alcanzaron en El Salvador es un tema aún por estudiar. Alvarenga sostiene que había una universidad popular por cada departamento del país: ALVARENGA, Patricia, Op. cit., p. 283.

${ }^{28}$ CÁRDENAS, Joaquín, Sucesos migueleños, San Miguel, Imprenta "El Progreso", (s.f.), p. 101; ANÓNIMO, "Elecciones en una Sociedad", en $L N, 6$ de abril de 1929, p. 4; CRONISTA ESPECIAL, "Por la Sociedad de Artesanos 'Esfuerzo y Cultura", en $L N, 17$ de abril de 1929, p. 1; CRONISTA ESPECIAL, "Por la Sociedad de Artesanos 'Esfuerzo y Cultura': sesión de viernes 3 del corriente", en $L N, 7$ de mayo de 1929, p. 1; ANÓNIMO, "Delegación Obrera", en Dor, 18 de junio de 1927, p. 1; ANÓNIMO, "Invitación”, en Dor, 18 de junio de 1927, p. 1; ANÓNIMO, "Conferencias", en Dor, 23 de junio de 1927, p. 4; ANÓNIMO, "San Miguel por dentro: nueva junta directiva", en Dor, 9 de abril de 1927, p. 3.

${ }^{29}$ ANÓNIMO, "Delegación Obrera”, en Dor, 18 de junio de 1927, p. 1; ANÓNIMO, "Invitación”, en Dor, 18 de junio de 1927, p. 1; ANÓNIMO, "Conferencias", en Dor, 23 de junio de 1927, p. 4; ANÓNIMO, "San Miguel por dentro: nueva junta directiva”, en Dor, 9 de abril de 1927, p. 3.

${ }^{30}$ ALVARENGA, Patricia, Op. cit., pp. 298-299.

${ }^{31}$ AGN, Fondo Gobernación-del Interior, Notas y Acuerdos, Ministerio de Gobernación, Segundo Semestre de 1927, Acuerdos, 5 de septiembre de 1927 y 12 de diciembre de 1927; ANÓNIMO, "Para los que tengan que tratar con la Junta de Conciliación”, en $L N, 17$ de enero de 1929, p. 1.
} 
Además de estas formas de organización social emanadas de los sectores populares urbanos, la infraestructura organizativa vigente en el municipio se ve complementada por la acción de las mismas elites locales, pues en su seno había nacido un movimiento reivindicativo que en otro escrito llamamos "orientalismo político", definido como una "[...] manifestación de las elites locales y regionales contra los déficits estatales -debemos agregar, del Estado posterior al auge cafetalero- en la región". La organización que impulsó esta agenda fue la Liga por el Progreso Oriental o Unión Oriental ${ }^{32}$.

Ahora bien, tenemos la hipótesis de que en la coyuntura de 1927-1932 esta infraestructura organizativa se articuló con una memoria colectiva del "populacho" migueleño. En efecto, como sostiene Aldo Lauria, por lo menos desde finales del siglo XVIII hasta el segundo tercio del siglo XIX, en San Miguel se gestó una cultura plebeya, manifestada en una tradición de movilización y una disposición cotidiana al levantamiento entre los sectores populares de la ciudad y zonas circundantes ${ }^{33}$. Sin embargo, después de la revuelta de 1875, la llamada "pequeña noche de San Bartolomé" y la represión que le siguió, esta tradición se disolvió. A raíz del ascenso de la agricultura comercial, la consolidación del aparato central -incluyendo el aparato represivo-y la difusión de una ideología modernizadora hacia los sectores populares, concretada en los proyectos de morigeración de las costumbres, muchos de sus sujetos (los indígenas) y repertorios se disolvieron mientras otras de sus expresiones entraron en un estado de latencia y de modificaciones por hibridación ${ }^{34}$.

De forma paralela a cómo el movimiento "comunalista" indígena del occidente salvadoreño reactualizaba la memoria sobre las tierras y la vida comunal de los indios antes de la privatización de 1880-1882, en la constitución de una conciencia radicalizada ${ }^{35}$; el populacho migueleño decimonónico ejecutó la reconstrucción memorialista de motivaciones, sociabilidades, definición de adversarios y repertorios

\footnotetext{
${ }^{32}$ GONZÁLEZ MÁRQUEZ, Luis Rubén, "Han ocurrido bochinches...", Op. cit., p. 10.

${ }^{33}$ Con el conflictivo período inmediatamente posterior a la independencia en el siglo XIX es cuando esta tradición se manifiesta plenamente en levantamientos populares que vinculaban la política local, regional y nacional. Hasta donde conocemos, hubo levantamientos en San Miguel en 1833-35, 1845, 1865 y 1875 , este último período fue estudiado en detalle por Lauria. Empero, no era algo particular de la ciudad, sucedía igualmente en otras regiones del país como en las zonas de los Nonualcos, fenómeno estudiado por López Bernal. Más bien era parte de la dinámica de negociación entre comunidades, gobierno y elites en la construcción del Estado salvadoreño. Las particularidades de los casos de San Miguel eran el contenido étnico antiblanco (en 1875 se pedía "pasar por el cuchillo a los blancos"), el teatro de acción citadino, el protagonismo de las vendedoras, artesanos y campesinos ladinos, el menor peso de las comunidades indígenas como actores y unas reivindicaciones que combinaban elementos tradicionales con modernos (como la consigna “;Viva la religión y muera el imperio!”). LAURIA, Aldo, "Holding the City Hostage...”, pp. 79-95; LARDÉ Y LARÍN, Jorge, El Salvador, historia de sus pueblos, villas y ciudades, San Salvador, DPI, 2000, pp. 436-440; López BernaL, Carlos Gregorio, "El levantamiento indígena de 1846...”, pp. 19-29.

${ }^{34}$ LÓPEZ BERNAL, Carlos Gregorio, "Poder central y poder local en la construcción del Estado en El Salvador, 1840-1890", Tesis doctoral, Universidad de Costa Rica, 2007, pp. 56-64; GONZÁLEZ MÁRQUEZ, Luis Rubén "Sociabilidad y organizaciones artesanales-obreras. La Sociedad de Artesanos El Porvenir de Santa Tecla, 1902-1932”, pp. 113-129 y 181-189.

${ }^{35}$ GOULD, Jeffrey, LAURIA, Aldo, Op. cit., pp. 64.
} 
de acción, como resistencia a las elites, esto fue una dimensión subyacente del ciclo de protestas en la localidad ${ }^{36}$, como se hace explícito en los casos que revisaremos en la próxima sección, especialmente en la construcción de la ideología populista y radical que sus protagonistas manifestaron.

Con esto último nos referimos a la apropiación de ideas, nociones, símbolos y prácticas "derivadas" de movimientos socialistas y radicales, en coherencia, conflicto y resignificación con la cultura "inherente" del populacho migueleño ${ }^{37}$. A pesar de que este proceso fue común en los movimientos populares de la época, la circulación previa a esta apropiación se realizó por canales y redes peculiares en la región oriental, dado que en este lugar la FRTS y el Socorro Rojo Internacional (SRI) no tuvieron mayor relevancia ${ }^{38}$. Constituyendo un tema pendiente por estudiar, creemos que el radicalismo llegó al oriente salvadoreño a través de la labor de la Universidad Popular de San Miguel y desde la lucha de Sandino en las cercanas Segovias nicaragüenses (Mapa 1) $)^{39}$.

Entonces, la apertura política del régimen de Romero Bosque representó una fisura que permitió el crecimiento de la movilización ante la oportunidad política, mientras su posterior cierre motivó un incremento y radicalización de las protestas ${ }^{40}$. En San Miguel esto se tradujo en el fortalecimiento de las organizaciones artesanales-obreras en proceso de radicalización, que hicieron suya la configuración de una memoria plebeya. Empero, en el marco de la estructura de poder de San Miguel y del oriente salvadoreño, la apertura política del Estado también representó un retiro de uno de sus basamentos, la coerción, que junto al proyecto de morigeración de las costumbres compensaba la debilidad en la hegemonía de las clases dominantes locales y regionales.

\footnotetext{
${ }^{36}$ Esto se manifestó en la vida cotidiana. Casos como los de la reacción al arresto del campesino Nicomedes Campos eran comunes en la prensa migueleña y merecen un estudio aparte: según La Nación, en marzo de 1929, Campos apuñaló a un policía y se lio a golpes con otros que lo arrestaron frente a una cantina. Como venganza los policías le daban una golpiza; ante esto, “[...] el numeroso público de mujeres y de hombres protestabagritos [sic] contra aquel proceder y entonces ocurrió algo singular [...] De uno de los grupos de los expectadores [sic] se desprendió un hombre y a un policial que en aquel momento aplicaba un puntapiés en la cabeza del reo le aplicó una bofetada en pleno rostro [...]". ANÓNIMO, "Un hombre riñó anteayer como con ocho policiales", en $L N, 19$ de marzo de 1929, pp. 1-4.

37 "Lo más frecuente es que sea (la ideología popular) una mezcla, una fusión de dos elementos [...] el primero es lo que yo llamo el elemento tradicional, 'inherente' [...] basada en la experiencia directa, la tradición oral o la memoria colectiva [...] el segundo elemento es el cúmulo de ideas y creencias que 'derivan' o se toman prestadas de las demás, y que a menudo se presentan como un sistema más estructurado de ideas políticas”. RUDÉ, Revuelta popular y conciencia de clase..., Op. cit., pp. 34-35.

${ }^{38}$ Por ejemplo, en una nómina de las 31 organizaciones que integraban la FRTS, sin fecha, se acusaba a tres de las cuatro asociaciones de base del oriente del país de ser "desorganizadas" (esto no se dice del resto de organizaciones). Además, la región carecía de un "cuerpo representativo" regional como los de la "Zona Central”, la "Zona Occidental” y Sonsonate. COMITERN, Documentos de El Salvador, 534-7-455, FRTS, "Federación Regional de Trabajadores de El Salvador: nómina de las organizaciones que la integran".

${ }^{39}$ En ello fueron cruciales los inmigrantes nicaragüenses exiliados y una opinión pública local-regional sensible a la situación del cercano país: ANÓNIMO, "Conferencias", en Dor, 23 de junio de 1927, p. 4; ORELLANA, Eduardo, "Prevención”, en Dor, 25 de mayo de 1927, p. 4; ANÓNIMO, "Por el bien de los trabajadores", en $L N, 23$ de enero de 1929, p. 2.

${ }^{40}$ ALMEIDA, Paul, Op. cit., pp. 49-51.
} 
Esto sucedía al mismo tiempo que se articulaba la crisis económica crónica con la crisis mundial, con las conflictividades directas e indirectas que alentaban. En este escenario irrumpieron distintos episodios de movilización social.

\section{Protestas populares en San Miguel, 1927-1932: análisis de casos}

Entre 1927 y 1932, la ciudad de San Miguel fue escenario de variadas formas de protesta popular. Aun así, tanto las modalidades de acción como los líderes involucrados se entrecruzaban en una movilización y otra. En otras palabras, existen conexiones entre unos movimientos y otros, por lo tanto, se vuelven momentos de un mismo proceso -pero no por ello menos multiforme-. Siendo así, es posible un análisis de las partes y desde allí partir a una reconstrucción más completa del conjunto. En tal sentido, en esta sección describiremos cada caso de acuerdo a las secuencias, los repertorios de acción, los sujetos, los líderes, los adversarios, los discursos y los objetivos desplegados ${ }^{41}$.

Los casos que analizamos son las manifestaciones antiimperialistas de 1927, un movimiento de protesta anti fiscal contra la alcaldía de 1929 y una revuelta popular en 1930. En este punto es necesario hacer una aclaración. Tenemos indicios de un significativo evento de movilización social en San Miguel que hemos excluido, una frustrada insurrección urbana y militar en el marco de la rebelión de 1932. El inconveniente es que de ella solo da cuenta una fuente literaria, la novela testimonial Miguel Mármol, de Roque Dalton. De confirmarse, esta representaría el cierre del ciclo de protestas y no la revuelta de octubre de 1930, con la cual guarda una íntima relación $n^{42}$.

\section{Movilización antiimperialista y "Pro Sacco y Vanzetti” de 1927}

La primera expresión de protesta popular que se gesta en San Miguel en este ciclo aparece en 1927, con el antiimperialismo como signo definitorio. Esto no es una casualidad. Durante la dinastía de los Meléndez-Quiñónez, unos de los pocos motivos de organización social y protesta tolerados -e incluso fomentados- fueron aquellos que se oponían al intervencionismo de Estados Unidos en América Latina ${ }^{43}$, un tema sensible desde la caída del gobierno de José Santos Zelaya en Nicaragua en 1909. Esta tolerancia a la movilización antiimperialista se entrelazó con la apertura política impulsada por el nuevo presidente Pío Romero Bosque, desde marzo de 1927. Es decir, en el primer trimestre de ese año continuaba la represión velada de Alfonso

\footnotetext{
${ }^{41}$ Ver notas al pie 4, 5,6.

${ }^{42}$ Según Roque Dalton, los mismos "sotistas" de octubre de 1930 participarían de la insurrección de 1932, con una milicia de 700 personas reunida en el cementerio de San Miguel. Con "el apoyo de dos compañías de soldados del Regimiento de San Miguel" efectuarían "una acción conjunta" de toma de la ciudad, fallida al final por falta de comunicación y también por la represión (según el mismo texto, muchos "sotistas" fueron encarcelados). DALTON, Roque, Miguel Mármol: los sucesos de 1932 en El Salvador, Melbourne, Ocean Sur, 2007, pp. 166, 185-195.

${ }^{43}$ LINDO-FUENTES, Héctor, “Anti-imperialismo salvadoreño, versión 1914”, El Faro Académico, 13 de enero de 2014, http://www.elfaro.net/es/201401/academico/14446/, consultado (15/01/2014).
} 
Quiñónez Molina, que se vio interrumpida por la política de respeto a las libertades civiles de Romero Bosque, giro que tomó algún tiempo en volverse creíble por ser este último un heredero del poder de la dinastía ${ }^{44}$.

En ese lapso, el discurso antiimperialista en circulación desde 1909, fundamentalmente patriótico, vivió un proceso de hibridación con la ideología populista-radical en gestación entre los sectores artesanales-obreros del país. Por lo menos inicialmente, esta radicalización antiimperialista obrera halló tolerancia desde las esferas gubernamentales, no solo por la apertura política referida, también porque el adversario que identificaban se encontraba convenientemente fuera de las fronteras del país: el "Imperialismo Yankee". En el caso del movimiento artesanal-obrero de San Miguel esa radicalización tuvo un enorme eco, si bien inicialmente aparecía velada por la censura gubernamental, en el segundo semestre de 1927 fue expresada sin complejos en la esfera pública, como lo muestran las manifestaciones antiimperialistas en la localidad (Cuadro 1).

Cuadro 1. Síntesis descriptiva de movilización antiimperialista y Pro-Sacco y Vanzetti en San Miguel, 1927

\begin{tabular}{|l|l|}
\hline Categoría & \multicolumn{1}{c|}{ Descripción } \\
\hline 1. Secuencia & $\begin{array}{l}\text { - Dos manifestaciones frustradas en enero de 1927 contra la intervención } \\
\text { estadounidense en Nicaragua. } \\
\text { - Manifestación Pro-Sacco y Vanzetti y contra intervención estadounidense } \\
\text { en Nicaragua, 21 de agosto de 1927. }\end{array}$ \\
\hline $\begin{array}{l}\text { 2. Repertorios y } \\
\text { formas de acción }\end{array}$ & - Desfile y discursos públicos en centro de la ciudad. \\
\hline $\begin{array}{l}\text { 3. Sujetos } \\
\text { (composición) }\end{array}$ & $\begin{array}{l}\text { - Artesanos-obreros } \\
\text { - Pequeños comerciantes } \\
\text { * Aliados: Diario La Nación y su director, Rubén Membreño }\end{array}$ \\
\hline 4. Líderes & $\begin{array}{l}\text { - Miembros de asociaciones artesanales-obreras: Antonio Mayorga, } \\
\text { Fermín Urquilla, César Coello, Román Cortés, Andrés Pineda, Federico } \\
\text { Moreno y Jesús Urquilla. }\end{array}$ \\
\hline 5. Adversarios & "Imperialismo Yankee" \\
\hline $\begin{array}{l}\text { 6. Discurso y } \\
\text { objetivos }\end{array}$ & $\begin{array}{l}\text { Poco conocidos. Destaca bandera rojinegra, por hibridación de motivos } \\
\text { del Ejército Defensor de la Soberanía de Nicaragua (EDSN), radicalismo } \\
\text { obrero y anarquismo de Sacco y Vanzetti. }\end{array}$ \\
\hline
\end{tabular}

Fuentes: Diario de Oriente, enero de 1927 y Diario del Salvador, agosto de 1927.

La secuencia de la protesta partió de dos manifestaciones frustradas en enero de 1927, en ambos casos por la censura del Ministerio de Gobernación y a pesar de la anuencia que el mismo manifestó ante otras movilizaciones similares en el resto del país. Seguramente esto obedecía tanto a la revitalización de la memoria plebeya migueleña como a la influencia de Augusto César Sandino y el Ejército Defensor de

\footnotetext{
${ }_{44}$ ANÓNIMO, "La asamblea levantó hoy el Estado de Sitio, el lunes será promulgado el decreto", en Dor, 14 de mayo de 1927, p. 4; LÓPEZ BERNAL, Carlos Gregorio, Tradiciones inventadas y discursos nacionalistas: El imaginario nacional de la época liberal en El Salvador, 1876-1932, San Salvador, Editorial Universitaria, 2007, p. 208.
} 
la Soberanía Nacional (EDSN) de Nicaragua en el oriente salvadoreño. Aun así, la expectación popular por una manifestación antiimperialista en San Miguel creció, al mismo tiempo que su discurso hallaba mayores canales de difusión. De esta manera, en agosto de 1927 se organizó exitosamente una movilización de solidaridad y protesta ante la inminente ejecución judicial en Estados Unidos de los anarquistas italianos Nicolás Sacco y Bartolomé Vanzetti. La clave articuladora de esta manifestación fue el poder conectar la mediática ejecución de Sacco y Vanzetti ${ }^{45}$ con la intervención estadounidense en Nicaragua:
Antes de las cuatro de la tarde comenzaron a llegar los manifestantes al Parque Barrios y cuando eran las cuatro había en aquél lugar un número considerable de obreros. En perfecto orden fue organizado el desfile que recorrió las principales calles de la ciudad [...] Todos aquellos no sólo se concretaron a protestar por la electrocutación [sic] que tiene amenazados a Sacco y Vanzetti, sino a condenar el imperialismo yanqui, que ya tiene puesta su férrea bota sobre el indefenso pueblo de Nicaragua ${ }^{46}$.

Al finalizar el desfile, los participantes emplearon el recurso del discurso público y estructurado en lugares estratégicos de poder del centro de la ciudad, tales como el "kiosco" del parque central, la "esquina opuesta al Palacio Episcopal", la "esquina de la Cámara Seccional" o "frente al Consulado Italiano" -probablemente también la casa de un miembro de origen italiano de la elite-. Ante estos discursos el público aplaudió "frenéticamente" ". Esta combinación del desfile y discurso público tiene una intención manifiesta de ser una protesta de cara a la esfera pública; asimismo, es una reformulación elaborada, por el movimiento artesanal-obrero local, del "mitin" o “meeting” de la política de masas de los países industrializados.

Se infiere de las fuentes que los participantes eran en su mayoría trabajadores urbanos ("obreros"), a quienes se sumaron vendedores y comerciantes. Mientras tanto el liderazgo provenía de las asociaciones artesanales-obreras de la localidad, promotoras de las frustradas manifestaciones antiimperialistas de principios de año, momento en el que incluso fundaron "un Comité Obrero Anti-imperialista" (liderado por Antonio Mayorga) que funcionó como matriz unificadora en la coyuntura inmediata de estas organizaciones $^{48}$.

En lo referente al discurso, las limitadas notas de prensa al menos dejan en claro la combinación de motivos antiimperialistas con otros del radicalismo obrero. De esa hibridación da cuenta el simbolismo referente al color de la bandera "rojinegra" que antojadizamente el redactor de la nota califica de "comunista". A pesar de esto, creemos que este símbolo se retomó del EDSN, de la popular lucha de Sandino, así

\footnotetext{
${ }^{45}$ Por ejemplo, las portadas de estos periódicos: Dor, 2 de junio de 1927, p. 1; El Día, San Salvador, 8 de agosto de 1927, p. 1, 10 de agosto de 1927, p. 1, 17 de agosto de 1927, p. 1, 19 de agosto de 1927, p. 1.

${ }^{46}$ ANÓNIMO, "Ecos del Mitin Pro-Sacco y Vanzetti en San Miguel", en Diario del Salvador (DES), San Salvador, 25 de agosto de 1927, p. 4; ANÓNIMO, "Ecos de un mitin socialista", en DES 23 de agosto de 1927, p. 8. Énfasis nuestro.

${ }^{47}$ ANÓNIMO, "Ecos de un mitin socialista", en DES, 23 de agosto de 1927, p. 8.

${ }^{48}$ MAYORGA, Antonio, "Lo que dice el señor Mayorga", en Dor, 23 de enero de 1927, p. 4.
} 
mismo aglutinaba el color-símbolo negro de los anarquistas Sacco y Vanzetti, sumado a esto como otro elemento confluyente en esta relación sincrética, también representaba un difuso radicalismo más allá de las fronteras doctrinarias poco distinguibles en las bases del movimiento artesanal-obrero y popular de El Salvador ${ }^{49}$.

Entonces, la indignación por la inminente ejecución de Sacco y Vanzetti, un proceso naciente de radicalización de diferentes expresiones organizativas artesanalesobreras y un contexto de reciente apertura política, confluyeron en una anteriormente pospuesta y redefinida manifestación antiimperialista contra la intervención estadounidense en Nicaragua. Pospuesta porque la censura gubernamental había frustrado los intentos previos de unos colectivos de los sectores subalternos de San Miguel. Redefinida por la circulación, apropiación y restablecimiento de una ideología radical difusa entre los artesanos-obreros, con elementos proletarios, populistas y socialistas, que permitían asumir la popular protesta antiimperialista y al mismo tiempo darle otros contornos.

\section{Protestas contra el proyecto de Tarifa de Arbitrios municipales de 1929}

Un segundo episodio de movilización en San Miguel durante el ciclo 1927-1932 se vivió a mediados de 1929. Entre las motivaciones se combinaron disputas de poder local y los efectos de la crisis económica mundial en la localidad, perjuicios materializados en un proyecto de modificación a la Tarifa de Arbitrios Municipales presentado en febrero de ese año por el ayuntamiento migueleño ante las autoridades superiores, Gobernación Departamental, Ministerio de Gobernación y Asamblea Nacional, para su aprobación. Según el documento del proyecto de Tarifa de Arbitrios, transcrito por la prensa local, en los nuevos impuestos y en los aumentos se gravaban algunas actividades de sectores populares, incluyendo los propietarios de talleres artesanales y vendedores ambulantes; de los sectores medios, los dueños de tiendas y tenerías; de una parte de la elite migueleña, la prestamista en usura o la comerciante de granos básicos a gran escala ${ }^{50}$.

La municipalidad deseaba aumentar la recaudación para paliar los efectos de la crisis fiscal del Estado, agravada por el reencauzamiento de los recursos destinados a las localidades hacia el aparato central. Como apuntaba un regidor defensor del proyecto y líder obrero de la Sociedad Esfuerzo y Cultura, Román Cortés:

[...] nadie ignora desde la primera autoridad política del Departamento hasta el más humilde de los trabajadores que han protestado, que las rentas municipales han sido diezmadas en un alto porcentaje por el Gobierno de la Nación. Las Tesorerías municipales en la actualidad están casi convertidas en oficinas recaudadoras de la Tesorería Nacional ${ }^{51}$.

\footnotetext{
${ }^{49}$ Dos estudios que lo reflejan: GOULD, Jeffrey, LAURIA, Aldo, Op. cit., p. 110; DALTON, Roque, $O p$. cit., pp. 109-115.

${ }^{50}$ MUNICIPALIDAD DE SAN MIGUEL, "Tarifa de arbitrios elaborada por la Municipalidad de San Miguel", en $L N$, 4 de junio de 1929, pp. 1-3-5, de Junio de 1929, pp. 1-2.

${ }^{51}$ CORTÉS, Román, "Los Regidores Cortés y Valle Coto dan explicaciones sobre el asunto Tarifa”, en $L N$,
} 
Había un interés encontrado entre las necesidades financieras del poder local y la situación de los distintos sectores sociales afectados con la subida de impuestos en medio de una crisis económica global que se agregaba a la depresión crónica de San Miguel. Al mismo tiempo, la municipalidad se presentaba como un adversario común entre distintos, incluso contrapuestos, sectores sociales de la localidad.

A pesar de la gravedad de estas motivaciones, vale la pena considerar otros condicionantes de la protesta. Primero, nos encontramos con una disputa por el poder local entre distintas facciones, lo que originaba que el grupo desplazado cuestionara la legitimidad del que se había agenciado la administración municipal ${ }^{52}$. En segundo lugar, las divisiones en los diferentes eslabones de poder estatal hallaron motivo para tensarse con el proyecto de Tarifa de Arbitrios, estas aparecieron como oportunidad política para la protesta: por una parte, la alcaldía de San Miguel se encontraba en una disputa con el gobernador departamental y exalcalde de la misma localidad entre 1924 y 1927, el médico Baltazar Zapata ${ }^{53}$; asimismo, la municipalidad no era un todo cohesionado, dado que la actuación ambigua de uno de sus regidores, el "obrero" Antonio Valle Coto, la hizo aparecer dividida y débil en la arena pública ${ }^{54}$.

Esta división de poder también alcanzaba a las organizaciones artesanalesobreras, las más importantes e influyentes de los sectores subalternos migueleños. Como en otras partes del país, el prestigio logrado por estas organizaciones les había permitido a sus liderazgos acceder a cuotas de poder local ${ }^{55}$. En el Concejo Municipal de San Miguel de 1929 encontramos a los mencionados Valle Coto, Román Cortés y José Antonio Benavides, llamados por la prensa "la trilogía obrera en el ayuntamiento". Ahora bien, al constituir la Tarifa de Arbitrios - un proyecto que afectaba directamente a los artesanos-obreros-y al ser el poder municipal el proponente de estas reformas, se fortalecieron las divergencias entre los líderes artesanos-obreros en el concejo y la mayor parte del movimiento artesanal-obrero. En este escenario conflictivo irrumpió la protesta contra la Tarifa de Arbitrios (Cuadro 2).

\footnotetext{
9 de junio de 1929, pp. 1-6. Énfasis nuestro.

${ }^{52}$ Un escenario, como ha demostrado Erik Ching, consustancial a la estructura de poder piramidal, clientelar y de patronazgo vigente en El Salvador. CHING, Erik, "Patronage and Politics under General Maximiliano Martínez, 1931-1939: The Local Roots of Military Authoritarianism in El Salvador", en BINFORD, LAURIA, Aldo, Landscape of Struggle..., pp. 55-58.

${ }^{53}$ CÁRDENAS, Joaquín, Op, cit., p., 74.

${ }^{54}$ Aunque al final de cuentas Valle Coto votó por el proyecto de Tarifa de Arbitrios, "por disciplina" de someterse "a la mayoría", dijo haber hecho: "[...] lo que me fué [sic] posible para que en el ya dicho proyecto no se anotaran impuestos gravosos para la clase a que pertenezco". VALLE COTO, A., "Los Regidores Cortés y Valle Coto dan explicaciones sobre el asunto Tarifa", en $L N, 9$ de junio de 1929, pp. 1-6.

${ }^{55}$ GONZÁLEZ MÁRQUEZ, Luis Rubén, “Sociabilidad y organizaciones artesanales-obreras...”, Op. cit., pp. 217-227.
} 
Cuadro 2. Síntesis descriptiva del movimiento contra la Tarifa de Arbitrios Municipales en San Miguel, 1929

\begin{tabular}{|c|c|}
\hline Categoría & Descripción \\
\hline 1. Secuencia & $\begin{array}{l}\text { - Preparación y difusión de manifiestos escritos entre el } 6 \text { y el } 9 \text { de } \\
\text { junio. } \\
\text { - Protesta popular el } 9 \text { de junio de } 1929 \text {. } \\
\text { - Difusión de manifiestos públicos del } 11 \text { al } 27 \text { de junio de } 1929 . \\
\text { - Frustrada movilización de mujeres el } 16 \text { de junio de } 1929 . \\
\text { - Frustrada organización de "meeting” (movilización a gran escala) en } \\
\text { la última semana de junio de } 1929 \text {. } \\
\text { - Retiro de Proyecto de Tarifa de Arbitrios por municipalidad el } 27 \text { de } \\
\text { junio de } 1929 .\end{array}$ \\
\hline $\begin{array}{l}\text { 2. Repert } \\
\text { formas d }\end{array}$ & $\begin{array}{l}\text { - Desfile y discursos públicos en el centro de la ciudad. } \\
\text { - Manifiestos colectivos, difundidos en la esfera pública (prensa y } \\
\text { hojas volantes). } \\
\text { - Manifiestos individuales, difundidos en prensa. }\end{array}$ \\
\hline $\begin{array}{l}\text { 3. St } \\
\text { (com }\end{array}$ & $\begin{array}{l}\text { - Artesanos-obreros } \\
\text { - Vendedoras de los mercados } \\
\text { - Pequeños comerciantes } \\
\text { - Profesionales (solo en manifiestos escritos). } \\
\text { - Algunos miembros de la elite local, incluyendo miembros de facción } \\
\text { Meardi (solo en manifiestos escritos). } \\
\text { * Aliados: Diario La Nación y Gobernador Departamental de San } \\
\text { Miguel, Baltazar Zapata. }\end{array}$ \\
\hline 4. Líderes & $\begin{array}{l}\text { - Miembros de organizaciones artesanales-obreras locales: Leopoldo } \\
\text { Chavarría, Jesús Urquilla, Andrés Pineda Elena y Alfonso Novoa. } \\
\text { - Anónimas: vendedoras de mercados. }\end{array}$ \\
\hline 5. Adversarios & - Alcaldía de San Miguel \\
\hline $\begin{array}{l}\text { 6. Discurso y } \\
\text { objetivos }\end{array}$ & $\begin{array}{l}\text { - Discurso proletario y obrero intercalado con populismo. Equivalencia } \\
\text { sectores populares y proletariado. } \\
\text { - Discurso de traición de clase por artesanos-obreros en concejo } \\
\text { municipal y demanda de patriotismo con reforma social. } \\
\text { - Discurso de municipalidad y el Estado como exclusivamente } \\
\text { representantes de intereses de sectores populares. Por lo tanto, traición } \\
\text { de alcaldía. } \\
\text { - Discurso de democratización del poder municipal e ilegitimidad del } \\
\text { concejo municipal. } \\
\text { - Objetivos: retiro de proyecto de arbitrios y condena al concejo, sobre } \\
\text { todo a la "trilogía obrera". Después, implícitamente, se agregó la } \\
\text { presión por la renuncia del concejo municipal en pleno. }\end{array}$ \\
\hline
\end{tabular}

Fuentes: La Nación, Junio de 1929; Diario de Oriente, Junio de 1929 y AGN, Fondo Ministerio de Gobernación-Del Interior, Despacho del Ministro, Copiador de Notas y Acuerdos, 1929, Libro de Julio, 5.4, 4 de julio de $1929, \mathrm{~N}^{\circ} 4630$.

Este movimiento de protesta estuvo activo casi todo el mes de junio, incluyendo una multitudinaria manifestación el domingo 9 del mismo mes, que siguió un patrón que intercalaba un desfile por el centro de la ciudad y paradas para escuchar discursos públicos. El repertorio es muy parecido al acontecido en agosto de 1927 
e igualmente se pensó aplicarlo en el frustrado "Meeting" de finales de junio de $1929^{56}$. La novedad la constituye el recurso a los manifiestos, tanto colectivos como individuales, redactados por artesanos y pequeños comerciantes, difundidos en hojas volantes y publicados tres días después en la prensa. En fechas posteriores se agregaron otros manifiestos individuales y tres manifiestos colectivos publicados en prensa ${ }^{57}$ : un "Memorial de los comerciantes, agricultores, artesanos y vecinos de esta ciudad" (14 de junio), un manifiesto de los "profesionales" de la ciudad (20 de junio) y un manifiesto de unas "Obreras Migueleñas" (27 de junio). En todos los casos con el objetivo de presionar a las autoridades estatales para el retiro del proyecto tarifario ${ }^{58}$.

También es notable la composición del movimiento, pues la constitución de una amplia alianza multiclasista es una de las claves de su éxito. Sin embargo, se vuelve impostergable ponderar el rol jugado por los distintos actores. En ese sentido, el protagonismo se encuentra entre los artesanos-obreros y las vendedoras de los mercados, como líderes. En el caso de los primeros, en la protesta del 9 de junio se convirtieron en los principales gestores, ya que la comisión que la organizó estaba "integrada por propietarios de taller y por operarios", de hecho, una nota de prensa destacaba "los elementos sobresalientes del obrerismo" asistentes a la manifestación ${ }^{59}$. En el caso de las vendedoras de los mercados, su liderazgo se muestra en sus intentos (postergados por el mismo éxito del movimiento) de organizar una manifestación de mujeres a mediados de junio y, más aún, por el rol que jugaron en la jornada del 9. Así describe el Diario de Oriente la llegada del desfile al mercado: "El mercado, que es como una colmena humana, en donde es especialmente la mujer la que vive consagrada a las faenas de la vida, cuando la manifestación pasó, era como un clamoroso mar. Todas formaron parte de ella" ${ }^{60}$. De igual forma, los participantes eran caracterizados como "el pueblo migueleño": "[...] grupos de ciudadanos y de mujeres -la exclusión de la mujer de la categoría "ciudadano" merece un análisis aparte- de la clase pobre, de esas que trabajan de sol a sol para ganarse su propio alimento y el de su familia" ${ }^{\text {. }}$.

\footnotetext{
${ }^{56}$ No se llevó a cabo porque la alcaldía retiró el proyecto. ANÓNIMO, "Se prepara un gran meeting en esta ciudad", en Dor, 21 de junio de 1929, p. 1.

${ }^{57}$ SAMAYOA, Arturo, "La tiránica Tarifa de Arbitrios Municipales", en $L N, 11$ de junio de 1929, p. 1; CHAVARRÍA, Leopoldo, "La tarifa de arbitrios elaborada por esta municipalidad lesiona los intereses de la comunidad", en $L N, 11$ de junio de 1929, p. 4; Obreras Migueleñas, "La contestación del municipio. Se Pide el Retiro de la Onerosa Tarifa", en Dor, 27 de junio de 1929, p. 1; SÁNCHEZ, Angel [sic], "Pluma obrera: los proletarios no son manada de borregos", en $L N, 23$ de junio de 1929, p. 1.

${ }^{58}$ CARÍAS et al, "Memorial de los comerciantes, agricultores, artesanos y vecinos", en $L N, 14$ de Junio de 1929, p. 1; CORDERO ROSALES et al, "Los profesionales migueleños se declaran contra la Tarifa de Arbitrios Municipales”, en $L N, 20$ de junio de 1929, p. 1.

${ }^{59}$ Como " $[. .$.$] don Alfonso Novoa, presidente de la sociedad de artesanos 'Esfuerzo y Cultura' y casi todos$ los miembros de la junta directiva de esa agrupación y muchos de sus socios; casi todos los miembros de la sociedad "Unión de Obreros". ANÓNIMO, "La brillante jornada defensiva del pueblo migueleño", en $L N, 11$ de junio de 1929 , p. 1.

${ }^{60}$ ANÓNIMO, "La imponente manifestación popular de ayer", en Dor, 10 de junio de 1929, p. 1. Énfasis nuestro.

${ }^{61}$ ANÓNIMO, "La brillante jornada defensiva del pueblo migueleño", en $L N, 11$ de junio de 1929, p. 1.
} 
Mientras tanto, los sectores medios y de la elite local que participaron (incluyendo la dominante facción Meardi), lo hicieron de forma diferenciada, por ejemplo, endosaron su apoyo a las movilizaciones en manifiestos -y como veremos, trataron de reconducir su discurso radical según sus intereses-, lo cual reforzó la presión sobre las autoridades y ayudó a legitimar la protesta popular ante la opinión pública nacional y las clases dominantes asentadas en otras regiones del país.

También es importante llamar la atención sobre los discursos que rodearon a la protesta. En su contenido el eje fundamental fue una prédica obrerista y "proletaria" que ubicaba a estos grupos como principales afectados por la nueva Tarifa de Arbitrios. Pero es un discurso "proletario" desde una definición "populista" que entiende al "proletariado" como una identidad común de los diversos sectores populares, liderados por los trabajadores urbanos, y con un fuerte sentido nacionalista-localista. Como lo ilustra un cartel desplegado el 9 de junio: "QUEREMOS la grandeza de San Miguel, pero sin extorsionar al proletariado. No somos esclavos"62. Esta prédica fue reconocida por la elite y utilizada hábilmente como argumento contra los nuevos impuestos, omitiendo cualquier alusión a antagonismos sociales de cualquier tipo:

Se argüirá que no sólo la clase humilde es la gravada, que es la clase acomodada, pero no debe olvidarse el fenómeno que en Finanzas se llama la traslación y repercusión del impuesto, éste repercute, es decir, va a rebotar en último análisis, contra esa clase humilde y sufrida que constituye el proletariado ${ }^{63}$.

Es de notar que los autores de la anterior cita, autodenominados "profesionales" y muchos de ellos miembros de familias notables migueleñas, presentan una contradicción entre consumidores y grandes comerciantes con un alto potencial conflictivo en las condiciones vigentes de San Miguel.

No obstante, este discurso proletario-populista fue rechazado por los defensores de la Tarifa de Arbitrios, curiosamente con una crítica a su ambigüedad. Román Cortés, líder del movimiento artesanal-obrero y regidor municipal, apuntaba a un concepto clasista de "proletariado" para defender el proyecto tarifario:

La protesta de algunos dueños de taller y la de sus respectivos operarios de esas mismas empresas nos lo está diciendo. Los verdaderamente proletarios en casi nada se lesionan, pues al fin éstos son explotados por sus respectivos patrones. Los dueños de taller, estos ya no son proletarios; estos ya son otros tantos competidores en los negocios, y justo es que algo paguen por lo mucho que reciben ${ }^{64}$.

También debemos señalar que Cortés, como otros miembros del movimiento comunista salvadoreño coetáneo, demostraba una gran distancia cultural con las

${ }^{62}$ Ibid., Por supuesto, en este caso, combinada con una identidad localista migueleña.

${ }^{63}$ CORDERO ROSALES et al, "Los profesionales migueleños se declaran contra la Tarifa de Arbitrios Municipales", en $L N, 20$ de junio de 1929, p. 1.

${ }^{64}$ CORTÉS, Román, "Los Regidores Cortés y Valle Coto dan explicaciones sobre el asunto Tarifa [...]”, en $L N, 9$ de junio de 1929, pp. 1-6. 
expectativas y sentidos de las clases subalternas, a través de un vanguardismo elitista. De ahí que él y el resto de líderes artesanales-obreros en la alcaldía (Valle Coto y Benavides), se convirtieran en objeto de la indignación del movimiento popular contra la Tarifa de Arbitrios ${ }^{65}$.

Un eje discursivo secundario de este movimiento contra la Tarifa de Arbitrios se refiere a la necesidad de profundizar la democratización y representatividad de las autoridades locales, evidentemente consiste en un discurso alimentado por las reformas electorales de Pío Romero Bosque. Aun así, era asumido y resignificado con orientaciones distintas por las clases dominantes, sectores medios locales y las clases subalternas. El énfasis de las primeras era político, estratégicamente empleado en el marco de las disputas de poder local. Para las últimas, significaba la identidad plena entre gobierno y los intereses de los sectores populares (equivalentes a "pueblo" $)^{66}$.

En síntesis, esta movilización plural (aunque con intereses diferenciados), liderada por los sectores populares urbanos, que seguía el discurso proletario-populista y empleaba como formas de acción la manifestación, los discursos en la esfera pública y la presión mediática, aprovechó la tradición de protesta vigente, la consolidación de la apertura política de Romero Bosque y una profunda división entre distintas instancias políticas y sociales de la colectividad local, para alcanzar su objetivo de paralizar el proyecto de Tarifa de Arbitrios. Lo consiguió al grado que el concejo municipal consideró tan importantes la derrota y el cuestionamiento de su legitimidad como para intentar renunciar a sus cargos.

Además de lo anterior, como efecto de su éxito se reactivó un terror por la movilización del populacho de San Miguel en las clases dominantes afincadas localmente, que remitía a la memoria plebeya migueleña. Ese terror se manifestó como cautela o como alivio. Como cautela, con llamados a la prudencia del "pueblo"67. Y como alivio, al constatar la resolución pacífica del conflicto y con ello promover la superación de la tradición decimonónica: “[...] el pueblo migueleño ya no es el pueblo que sirvió de instrumento a los caudillos de barriada para realizar farsas vergonzosas, al grado que aún existe el rubor que aquellas comedias ocasionaron en las personas honradamente patrióticas" ${ }^{68}$.

Como mostraron los acontecimientos de un año después, dicho temor no era del todo injustificado ni las elites las únicas con capacidad de moldear la memoria popular.

\footnotetext{
${ }^{65}$ Como apuntaba una nota satírica "[...] la peor arrechura de los muchachos -los protestantes- es contra los pana (obreros) que están en la regiduría porque no se amarraron en su puesto los pantalones". Pancho, "Reportaje sintético a tres Regidores Municipales", en $L N, 13$ de junio de 1929, p. 1.

66 “[...] no se concibe [...] que una autoridad como el Consejo Municipal que según el espíritu de la ley y la tradición debe emanar de la voluntad popular, se convierta sin ninguna justificación, en verdugo de las clases proletarias de las cuales es directamente representante". MANCÍA D. A. et al, "Dos exposiciones firmadas por numerosos ciudadanos", en $L N, 12$ de junio de 1929, p. 1. Énfasis nuestro.

${ }^{67}$ ANÓNIMO, "La Hora de Prueba para el Pueblo Migueleño", en LN, 23 de junio de 1929, p. 1.

${ }^{68}$ ANÓNIMO, "La influencia de las nuevas corrientes", en $L N, 30$ de junio de 1929, p. 1. Énfasis nuestro.
} 


\section{Revuelta popular de octubre de $1930^{69}$}

El último episodio de este ciclo de acción colectiva en San Miguel es una revuelta a gran escala. A raíz de la condena de José Isaac Soto, un "reo menor", se levantaron manifestaciones multitudinarias que demandaron la anulación del fallo judicial y atacaron las casas y bienes de los involucrados en la sentencia. La multitud prácticamente tomó el pueblo por dos días, 22 y 23 de octubre. Como respuesta, el Gobierno de Romero Bosque decretó el estado de sitio y movilizó tropas. Curiosamente, el saldo de la protesta y de la represión subsiguiente no dejó ningún muerto.

Antes de conocer su secuencia, es necesario tener en cuenta el antecedente que representó el turbulento proceso judicial contra Isaac Soto. Este era un tenedor de libros, pintor y pequeño comerciante ${ }^{70}$ que desde finales de 1929 fue acusado de desfalco y estafa a la agencia del Banco Occidental administrada por la sociedad comercial de Meardi y Gavio en San Miguel, cuyos propietarios eran el farmacéutico Celeste Meardi y el médico Carlos Gavio, por un monto de 154996 02 colones. Soto había laborado en la referida agencia como cajero y encargado desde 1925. En la acusación de Meardi y Gavio se dice que Soto extrajo dinero a través de giros bancarios triangulados, los cuales utilizó para expandir sus negocios propios. Pero cuando el Banco Occidental decidió cerrar la agencia de San Miguel en agosto de 1929, Soto se vio obligado a confesar su delito frente a dos testigos claves, Oscar Oberholzer y Juan Cristiani, quienes también eran lugartenientes de Celeste Meardi.

En su defensa Soto dijo haber sido solo un beneficiario más de una estafa liderada por Meardi, en la cual también actuaron Oberholzer y Cristiani. Estos tres le tendieron una trampa y bajo amenazas le hicieron firmar las confesiones notariadas del delito. En seguida, estos mismos personajes lo mantuvieron "secuestrado" hasta el 17 de agosto y después lo entregaron a la policía, que lo mantuvo incomunicado hasta la acusación del 24 de agosto ${ }^{71}$. Es decir, Soto afirmaba su inocencia, además acusaba a Meardi y sus aliados de haber cometido el desfalco, de robarle, secuestrarle y amenazarle.

Estos fueron los argumentos contrapuestos de un proceso judicial que se alargó desde agosto de 1929 hasta 1931, cuando en unas circunstancias no aclaradas por las fuentes Soto fue liberado de cargos ${ }^{72}$. Empero, antes de su liberación, un jurado de San Miguel lo declaró culpable en octubre de 1930. A causa de ese acto se gestó la movilización

\footnotetext{
${ }^{69}$ Esta sección resume los hallazgos de: GONZÁLEZ MÁRQUEZ, Luis Rubén, "Han ocurrido bochinches..." Op. cit.

${ }^{70}$ MENA, Rolando, MORALES BALlESTEROS, Raúl, "San Miguel histórico, 1530-2011. Volumen I", San Miguel, Mena producciones, 2011, p. 14.

${ }^{71}$ ANÓNIMO, José Isaac Soto: pruebas irrecusables de su culpabilidad, San Salvador, Talleres de la Sociedad Tipográfica, 1931, pp. 17-49. Énfasis del texto.

${ }^{72}$ ROMERO, María Magdalena, RIVERA GARCÍA, Ana Erlinda, DEL TRÁNSITO JíMENEZ, Regina, "Monografía de la Ciudad de San Miguel", Casa de la Cultura de San Miguel-CONCULTURA, sin publicar, s.f., p. 13.
} 
que culminaría en la revuelta (Cuadro 3), pues Soto se ubicó en el imaginario colectivo migueleño como una víctima de la arbitrariedad de la facción Meardi; su condena representó el límite de lo tolerable dentro de la "economía moral de la multitud"73.

Cuadro 3. Síntesis descriptiva de la revuelta popular en San Miguel, octubre 1930

\begin{tabular}{|c|c|}
\hline Categoría & Descripción \\
\hline 1. Secuencia & $\begin{array}{l}\text { - Manifestaciones de solidaridad con Soto, } 22 \text { de octubre por la } \\
\text { mañana. } \\
\text { - Ritualización de un juicio popular, } 22 \text { de octubre por la mañana. } \\
\text { - Fiesta popular frustrada, mediodía del } 22 \text { de octubre. } \\
\text { - Protesta pública, } 22 \text { de octubre por la tarde y } 23 \text { de octubre por la } \\
\text { mañana. } \\
\text { - Revuelta popular, } 23 \text { de octubre por la tarde y noche. }\end{array}$ \\
\hline $\begin{array}{l}\text { 2. Repertorios y } \\
\text { formas de acción }\end{array}$ & $\begin{array}{l}\text { - Desfile y discursos públicos en el centro de la ciudad. } \\
\text { - Concentración y presión masiva. } \\
\text { - Ataques a propiedad. } \\
\text { - Amotinamiento. }\end{array}$ \\
\hline $\begin{array}{l}\text { 3. Sujetos } \\
\text { (composición) }\end{array}$ & $\begin{array}{l}\text { - Artesanos-obreros } \\
\text { - Vendedoras de los mercados y mujeres de sectores populares } \\
\text { urbanos. } \\
\text { - Pequeños comerciantes. } \\
\text { - ¿Campesinos? } \\
\text { * Aliados: inicialmente miembros de elites locales competidoras de } \\
\text { facción Meardi. }\end{array}$ \\
\hline 4. Líderes & $\begin{array}{l}\text { - Miembros de organizaciones artesanales-obreras: Antonio Mayorga, } \\
\text { Heriberto Romero y Fermín Urquilla. } \\
\text { - Mujeres de sectores populares urbanos: Herminia Escolán y otras } \\
\text { anónimas. } \\
\text { - Miembros de sectores populares urbanos: anónimos. }\end{array}$ \\
\hline 5. Adversarios & $\begin{array}{l}\text { - Jurado y Juez Raúl Ramos (condenaron a Soto). } \\
\text { - Celeste Meardi y Carlos Gavio (en menor medida el último) y su } \\
\text { abogado José Estrada. } \\
\text { - Oscar Obeholzer y Juan Cristiani (lugartenientes de Celeste Meardi). } \\
\text { - Mauricio Meardi y la facción hegemónica de la elite local (en última } \\
\text { fase). }\end{array}$ \\
\hline $\begin{array}{l}\text { 6. Discurso y } \\
\text { objetivos }\end{array}$ & $\begin{array}{l}\text { - Discurso martirial de José Isaac Soto. } \\
\text { - Discurso de justicia popular opuesta al capital y su capacidad } \\
\text { corruptora. } \\
\text { - Discurso nacionalista contra "extranjero pernicioso" con poder } \\
\text { económico. } \\
\text { - Objetivos: realización de un nuevo juicio y justo, castigo a } \\
\text { responsables de condena a Soto e implícitamente, al final, castigo y } \\
\text { expulsión de Mauricio Meardi y su facción de la elite. } \\
\text { * Poco difundidas por las fuentes. }\end{array}$ \\
\hline
\end{tabular}

Fuente: González Márquez, "Han ocurrido bochinches. La revuelta de San Miguel en octubre de 1930: movilización social y violencia colectiva de la muchedumbre citadina”.

${ }^{73}$ THOMPSON, Edward, Op. cit. 
La secuencia de la movilización inició antes del juicio a Soto y derivó en una revuelta popular a gran escala que solo finalizó con la represión de la Guardia Nacional y el Ejército. En su repertorio de formas de acción conjuntó el desfile y el discurso público, comunes a las anteriores protestas de este ciclo, con otras novedosas como la concentración pública durante el juicio y algunas retomadas de la tradición de movilización social decimonónica, tales como el amotinamiento y ataque a las propiedades, ajustado a las nuevas condiciones con una noción de proporcionalidad de la violencia: en ningún momento se atacaron personas, solo propiedades $^{74}$.

Según un peritaje militar fueron diez las casas atacadas, en su totalidad de personas que la multitud consideró involucradas en la condena de Soto ${ }^{75}$. En todas, por lo menos, se apedrearon exteriores como zaguanes y puertas. Particularmente en seis casas la multitud logró "franquear" y destruir una parte de sus mobiliarios o todos. En el último ataque, a la casa de Mauricio Meardi, cuando la movilización derivó en revuelta, hubo una diferencia cualitativa evidente: las acciones de saqueo fueron generalizadas, incluyendo el asalto a una caja de seguridad "[...] de la cual desaparecieron 7,000.00 colones" y un intento de incendio. Algunas fuentes incluso dan cuenta de acciones simultáneas de sublevación, como un ataque a las cárceles locales y una confrontación armada con la Guardia Nacional ${ }^{76}$.

En cuanto a los sujetos y liderazgos es notable la continuidad desde las protestas de 1929 contra la Tarifa de Arbitrios, con un protagonismo de artesanos-obreros y las vendedoras del mercado. En el caso de los primeros, todo parece indicar que existían sostenidas redes entre Soto y algunos trabajadores urbanos. En adición, durante el proceso judicial se cometieron agravios a algunos miembros artesanos-obreros que testificaron a favor de Soto y fueron arrestados en las primeras diligencias del juicio $^{77}$. Por el lado de las vendedoras, fueron cruciales en la gestación de la primera manifestación en la mañana del 22 de octubre, pues ellas dominaban su espacio de realización efectiva, el mercado.

También los liderazgos "máximos", como los llama Rudé, provinieron de miembros de las organizaciones artesanales-obreras, en concreto Mayorga, Romero y Fermín Urquilla. A ellos se sumó una mujer, Herminia Escolán, en cuya casa se fundó una instancia organizativa inicial que no se logró consolidar, el "Comité Pro Justicia". Sin embargo, por el carácter espontáneo de la revuelta fueron más importantes en la

\footnotetext{
${ }^{74}$ Sobre este elemento novedoso: GONZÁLEZ MÁRQUEZ, Luis Rubén, "Han ocurrido bochinches...", Op. cit., p. 25.

${ }^{75}$ ANÓNIMO, "Informe rendido al Sr. Presidente de la República Dr. Romero Bosque por la comisión nombrada para investigar los sucesos migueleños", en DES, 9 de noviembre de 1930, pág.8; ANÓNIMO, “El saqueo y la destrucción”, en Diario Latino, pp. 74-77.

${ }^{76}$ ANÓNIMO, "Graficas [sic] de los recientes sucesos de San Miguel”, en DES, 31 de octubre de 1930, p.1; ANÓNIMO, "La voz oficial de los acontecimientos migueleños", en DES 30 de octubre de 1930, p.8; ANÓNIMO, "Fue pacificado el distrito de San Miguel", en La Prensa, 25 de octubre de 1930, p. 4.

${ }^{77}$ ANÓNIMO, Proceso contra José..., Op. cit., pp. 35-38.
} 
dirección de las acciones los líderes "intermedios" y "pequeños" surgidos "de entre las mismas turbas", cuyo papel era "puramente local y temporal"78.

Finalmente, en cuanto al discurso y objetivos de este episodio, a pesar de la gran cantidad de notas de prensa casi todas obviaron este aspecto, haciendo salvedad de algunas consignas transcritas y un excepcional discurso de Antonio Mayorga. En este discurso público frente al juzgado, justo antes del inicio del juicio, Mayorga explicó los motivos de la manifestación:

Señores jurados, venimos a Uds. en demanda de justicia, nosotros sabemos que váis [sic] a juzgar a un inocente, y que si la ley con sus códigos hace aparecer culpable a más de una víctima, vuestra conciencia no estará esta vez con los códigos y las falsas declaraciones. Es por esto que, esperamos de vosotros señores, un veredicto absolutorio para don José I. Soto, porque es el que debe inspirar vuestras conciencias de ciudadanos probos y honrados [...] Por esto [...] este pueblo aquí presente, viene a protestaros adhesión y simpatía y a animaros para que apartando escrúpulos e intereses particulares no os dejéis llevar por la influencia del capital que por desgracia, es siempre el que triunfa, aunque no tenga la justicia... iiViva el pueblo honrado, que pide la libertad de don José Isaac Soto!! ${ }^{79}$

Debemos destacar el sentido de la justicia fundado en la honorabilidad y la poca confianza en el corrompido sistema judicial. Esta revuelta pretendía resistir a una nueva situación del poder oligárquico fuera de los límites tradicionalmente aceptados ${ }^{80}$, representada por el caso Soto. En esa lógica podemos pensar que la multitud al escuchar el veredicto creyera que el jurado y todo el proceso judicial habían sido corrompidos por la facción Meardi, equivalente al "capital". En ese sentido, los gritos de “¡abajo el capital!” que se expresaron en la revuelta, según unos diplomáticos norteamericanos ${ }^{81}$, manifiestan una ideología populista y radical expuesta en los movimientos anteriores.

También el populacho migueleño presentó sus reclamos y quejas en términos nacionalistas contra los extranjeros, no en cuanto tales, sino a los poderosos y opresivos. A Juan Cristiani se le gritó en el juicio "que si vergüenza tuviera ya se hubiera marchado del país". Y según otra fuente, la muchedumbre acusó a Mauricio Meardi de "extranjero pernicioso" $\$ 2$.

\footnotetext{
${ }^{78}$ La represión se concentró en los cabecillas. ANÓNIMO, "Informe rendido”, en DES, p.3; ANÓNIMO, "Examinemos serenamente", en DES, p. 8; ANÓNIMO, "La manifestación contra el Jurado culmino [sic] en lamentables acontecimientos", [¿Diario Latino?], San Salvador, 24 de octubre de 1930, citado en ANÓNIMO, Proceso contra José..., Op. cit., p. 110; RUDÉ, "Los movimientos de masas...", Op. cit, p. 19.

${ }^{79}$ ANÓNIMO, "Examinemos serenamente...", Op. cit., en DES, p.8.

${ }^{80}$ RUDÉ, “Los movimientos de masas...”, Op. cit., p.22.

${ }^{81}$ GOULD, Jeffrey, LAURIA, Aldo, Op. cit., p.104.

${ }^{82}$ Estos elementos pueden considerarse en la hibridación de una concepción tradicional y las ideas nacionalistas, antiimperialistas e incluso las campañas xenofóbicas contra los pequeños comerciantes de origen palestino. ANÓNIMO, "Examinemos serenamente", en DES, pp. 1-8; Enviado especial, "No hubo
} 
En resumen, la revuelta de octubre de 1930 en San Miguel tuvo su origen en el proceso judicial contra José Isaac Soto. En la secuencia de los hechos, pasó de ser una manifestación de solidaridad con Soto a una revuelta antioligárquica. En ese cambio se transfiguraron los adversarios: de los involucrados en la condena de Soto a Mauricio Meardi, oligarca dominante. Posiblemente también el discurso se transformó, pero las fuentes no nos permiten constatarlo, solo dejan en claro que los motivos de la multitud estaban igualmente imbuidos de concepciones tradicionales y de las nuevas ideas radicales, en una compleja dinámica de hibridación dentro de la cultura popular. Por último, no debemos dejar de enfatizar que en la composición de esta acción colectiva predominaron los sectores populares urbanos en concreto, como en anteriores escenarios de protesta en la localidad, los artesanos-obreros, por su perfil como intelectuales del bajo pueblo, y las vendedoras del mercado, por su dominio del lugar central de sociabilidad pública.

\section{Conclusión}

A pesar de los límites de acceso a fuentes, cuando se observa desde el lente de lo local la ola de movilización que recorrió al país durante 1927-1932, en este caso desde una ciudad de mediano tamaño de la región oriental (San Miguel), queda claro que debemos abandonar cualquier idea de "rezago" de este espacio frente a la zona centro-occidental, en lo referente a la activación de la movilización popular o a la circulación-apropiación de discursos radicales. Más bien, nos encontramos con un ciclo de protesta que obedecía a la conjunción de tendencias nacionales, regionales y locales, en interacción, que proporcionaba de sus entornos concretos las formas de protesta, los participantes y las motivaciones.

En tal sentido, las condiciones de posibilidad de este ciclo de movilización social en San Miguel constituían, en primer lugar, una crisis económica crónica de la región oriental conjuntada con los efectos de la crisis económica mundial del país, como foco directo de conflictividad o presión que exacerbaba otras tensiones sociales, especialmente entre los sectores que conformaban el "populacho urbano" de San Miguel, los artesanos-obreros y los pequeños comerciantes informales, además una elite local con un poder concentrado en la facción Meardi. En segundo lugar, una infraestructura organizativa integrada por entidades artesanales-obreras de gran arraigo y legitimidad entre los sectores populares, relativamente alejadas de los circuitos orgánicos del movimiento obrero de San Salvador. Y en tercer lugar, una reactivación de la cultura plebeya a través de la memoria de la tradición decimonónica de movilización del populacho migueleño.

Cuando a estas condiciones se suma la oportunidad política representada por la liberalización del gobierno de Romero Bosque, la apropiación de una ideología populista radical -difundida desde San Salvador y las no tan lejanas Segovias nicaragüenses-y las motivaciones inmediatas de cada caso, el panorama del ciclo de

acusación contra J. I Soto", en Diario La Época, 30 de octubre de 1930, citado en ANÓNIMO, Proceso contra José..., Op. cit., p. 96; GUIDOS VÉJAR, Rafael, Op. cit., pp. 146-147. 
protestas en San Miguel queda completo. Hasta donde sabemos este ciclo tuvo tres momentos que demuestran una tendencia ascendente de radicalización en los medios y fines de la protesta: 1) Manifestaciones antiimperialistas contra la intervención de Estados Unidos en Nicaragua y contra la ejecución de Sacco y Vanzetti en el primer semestre de 1927; 2) Una movilización contra un proyecto de Tarifa de Arbitrios Municipales en junio de 1929; 3) Una revuelta popular antioligárquica inicialmente motivada por el caso Soto-Meardi en octubre de 1930. Además, queda sin confirmar un cuarto momento, un episodio frustrado de insurrección urbana y militar durante la rebelión de 1932.

Por otra parte, la magnitud de la participación popular también fue creciente, cerca de mil personas en 1927 y cuatro mil en 1930. En perspectiva similar el protagonismo jugado por los artesanos-obreros y las mujeres de los sectores populares, principalmente las vendedoras del mercado, fue constante. Desde estos grupos surgieron las iniciativas de movilización, así como los líderes e intelectuales. Las formas de acción del ciclo de protestas (como la manifestación tipo "mitin", la publicación de manifiestos o la revuelta y ataque contra las propiedades) demuestran una gran riqueza de repertorios, que combinaban tanto los adaptados durante la campaña de morigeración de costumbres como los provenientes de la memoria del populacho migueleño. Estas formas de acción se emplearon contra unos adversarios cambiantes, definidos por el motivo inmediato de la protesta: el imperialismo estadounidense, la municipalidad y la facción dominante de la elite local. En ningún caso se tomó al Estado o a una clase social como contrincantes objeto de la protesta, esto fue así tanto por convicciones asumidas como por consideraciones estratégicas acerca de los límites de su poder.

Difícilmente se podrá argüir falta de radicalidad o rechazo a idearios radicales, populistas y socialistas, en San Miguel. Obviamente ese proceso no cumplió las expectativas de los cuadros e intelectuales radicales del resto país, porque pasó por un complejo proceso de apropiación y resignificación. Al contrario, la aparición de un "populismo socialista", como lo llaman Gould y Lauria, en San Miguel es de una magnitud más cercana que en otras regiones del país e igualmente tiene en estas organizaciones y protestas un canal privilegiado de producción y reproducción. Sin embargo, la distancia cultural entre las bases y el muy pequeño grupo de líderes que habían asumido una militancia orgánica, así como la debilidad de las redes con el incipiente movimiento comunista (FRTS y SRI), dificultaron una dinámica de incorporación organizativa de los sectores populares urbanos migueleños. Es decir, desde el lenguaje (gramsciano) de Juan Carlos Portantiero y Emilio de Ípola, en San Miguel asistimos a una expresión “plural” de "desagregación de lo 'nacional-popular' en relación con lo 'nacionalestatal"”, pero sin lograr que en "ese campo de lucha” operara efectivamente una "reforma intelectual y moral"

\footnotetext{
${ }^{83}$ PORTANTIERO, Juan Carlos, DE ÍPOLA, Emilio, "Lo Nacional Popular y Los Populismos Realmente Existentes", en Nueva Sociedad, No. 54, Caracas, Friedrich Ebert, Junio 1981, pp. 5 y 7.
} 


\section{Fuentes}

\section{Fuentes primarias}

\section{Archivos}

Archivo General de la Nación:

- Fondo Ministerio de Gobernación-del Interior, Reglamentos y estatutos, 1923.

- Fondo Ministerio de Gobernación-del Interior, Despacho del Ministro, 1927-1930.

Comintern:

- Documentos de El Salvador, s.f.

\section{Publicaciones seriadas}

Biblioteca Nacional:

- Diario del Salvador, 1927- 1930.

- Diario Latino, 1927-1930.

- Diario de Oriente, 1929.

- La Nación, 1927-1929.

- El Blog, 2014.

Biblioteca del Museo Nacional de Antropología "David Joaquín Guzmán”:

- El Día, 1929-1930.

Documentación primaria impresa

ANÓNIMO, José Isaac Soto: pruebas irrecusables de su culpabilidad, San Salvador, Talleres de la Sociedad Tipográfica, 1931.

\section{Fuentes secundarias}

\section{Libros}

ALMEIDA, Paul, Olas de movilización popular: movimientos sociales en El Salvador, 1925-2010, San Salvador, UCA Editores, 2011.

ALVARENGA, Patricia, Cultura y ética de la violencia: El Salvador, 1880-1932, San José, EDUCA, 1996.

AVENDAÑO, Xiomara, La formación histórica del oriente salvadoreño: territorio, división político administrativa e identidad (inédito), Centro de Investigaciones Científicas-Universidad de El Salvador, marzo de 2014.

BARBERENA, Santiago, Monografias departamentales, San Salvador, Dirección de Publicaciones e Impresos, 1998. 
Protesta popular en San Miguel: repensar la ola de movilización social de 1927-1932...

BERMÚDEZ, Alejandro, El Salvador al vuelo, San Salvador: s.e., 1917.

BULMER-THOMAS, Víctor, La economía política de Centroamérica desde 1920, San José, Banco Centroamericano de Integración económica-EDUCA, 1989.

CÁRDENAS, Joaquín, Sucesos migueleños, San Miguel, Imprenta “El Progreso”, s.a.

CHARLAIX DE MUSCHENBORN, Ginny, San Miguel: historia, tradiciones, Carnaval: una visión de San Miguel desde la prehistoria al Carnaval, San Miguel, [s.n.], 2010.

DALTON, Roque, Miguel Mármol: los sucesos de 1932 en El Salvador, Melbourne, Ocean Sur, 2007.

Fernández, José Antonio, Pintando el mundo de azul: el auge añilero y el mercado centroamericano, 1750-1810, San Salvador, DPI, 2003.

GOULD, Jeffrey, Lauria, Aldo, 1932: rebelión en la oscuridad, San Salvador, Ediciones Museo de la Palabra y la Imagen, 2008.

GUIDOS VÉJAR, Rafael, El ascenso del militarismo en El Salvador, San José, Editorial Universitaria Centroamericana, 1982.

LAURIA, Aldo, Una República agraria: los campesinos en la economía y la política de El Salvador en el siglo XIX, San Salvador, DPI, 2003.

LINDO-FUENTES, Héctor, La economía de El Salvador en el siglo XIX, San Salvador, DPI, 2002.

LÓPEZ BERNAL, Carlos Gregorio, Tradiciones inventadas y discursos nacionalistas: El imaginario nacional de la época liberal en El Salvador, 1876-1932, San Salvador, Editorial Universitaria, 2007.

MEJÍA PÉREZ, José, Censo del $1^{\circ}$ de mayo de 1930, San Salvador, Dirección General de Estadística, 1939.

MENA, Rolando y MORALES, Raúl, San Miguel histórico, 1530-2011, Vol. 1, San Miguel, Mena producciones, 2011.

ROMERO, María Magdalena, RIVERA GARCÍA, Ana Erlinda y DEL TRÁNSITO JÍMENEZ, Regina, Monografía de la Ciudad de San Miguel, Casa de la Cultura de San Miguel-CONCULTURA (sin publicar), s.f. Biblioteca de la Casa de la Cultura de San Miguel.

RUDÉ, George, Revuelta popular y conciencia de clase, Barcelona, Critica, 1981. 
RUDÉ, George, Protesta popular y revolución en el siglo XVIII, Barcelona, Editorial Ariel, 1978.

THOMPSON, Edward, Tradición, revuelta y conciencia de clase, $2^{\circ}$ ed. Barcelona, Crítica, 1984.

WILSON, Evertt Alan, La crisis de la integración nacional en El Salvador: 19191935, San Salvador, Dirección de Publicaciones e Impresos, 2004.

\section{Capítulos de libros}

ACUÑA ORTEGA, Víctor Hugo, "The Formation of the Urban Middle Sectors in El Salvador, 1911-1944”, en BINFORD, Leigh, LAURIA, Aldo (Eds.), Landscape of Struggle: Politics, Society and Community in El Salvador, Pittsburgh, University of Pittsburgh Press, 2004. pp. 39-49.

GONZÁLEZ MÁRQUEZ, Luis Rubén. "Han ocurrido bochinches. La revuelta de San Miguel en octubre de 1930: movilización social y violencia colectiva de la muchedumbre citadina", en BERGMANN, Adrián y MELÉNDEZ, Óscar (Eds.), La violencia en los tiempos de paz: vida cotidiana y políticas públicas en El Salvador, San Salvador, Dirección Nacional de Investigaciones en Cultura y Arte de la Secretaría de Cultura, 2015 (En prensa).

HERNÁNDEZ, Carlos, “Ampliando perspectivas, reduciendo escalas: el mundo del trabajo, la movilización y la protesta social en perspectiva regional comparada", en CHEN MOK, Susana, MALAVASSI AGUILAR, Ana Paulina y VIALES, Ronny (Ed.), Teoría y métodos de los estudios regionales y locales, San José, Sistema Editorial de Difusión Científica de la Investigación-Universidad de Costa Rica, 2008.

\section{Artículos}

GOICOVIC DONOSO, Igor, "Consideraciones teóricas sobre la violencia social en Chile (1850-1930)", en Última década, No. 21, Santiago de Chile, diciembre de 2004, pp. 121145.

GONZÁlEZ, Luis, AGUIRRE ROJAS, Carlos Antonio y ASSAD, Carlos, "Mesa redonda: microhistoria italiana, microhistoria mexicana e historia local", en Relaciones, Vol. XXVI, Michoacán, COLMICH, 2005, pp. 193-224.

LAURIA, Aldo, "Holding the City Hostage: Popular Sectors and Elites in San Miguel, El Salvador, 1875", en The Americas, Vol. 68, No 1, Julio de 2011, pp. 63-95.

LÓPEZ BERNAL, Carlos Gregorio, "El levantamiento indígena de 1846 en Santiago Nonualco. Conflictos locales, etnicidad y lucha de facciones en el Salvador", en Revista de historia, No. 42, San José, Universidad de Costa Rica, 2000. pp. 9-41. 
Protesta popular en San Miguel: repensar la ola de movilización social de 1927-1932...

LÓPEZ BERNAL, Carlos Gregorio, "Historiografía y movimientos sociales en El Salvador (1811-1932): un balance preliminar", en Revista de historia, No. 67, San José, Universidad de Costa Rica, junio de 2013. pp. 89-119.

PORTANTIERO, Juan Carlos y DE ÍPOLA, Emilio. "Lo Nacional Popular y Los Populismos Realmente Existentes", en Nueva Sociedad, No. 54, Caracas, Friedrich Ebert, Junio 1981. pp. 7-18.

POLO BUITRAGO, Sandra Milena, "Movilización popular en Bogotá en la segunda mitad del siglo XIX: el caso del Motín del Pan del 23 de enero de 1875", en Historia Crítica No. 35, Bogotá, Universidad de los Andes, junio de 2008, pp. 16-33.

ROMERO, Luis Alberto, "Los sectores populares urbanos como sujetos históricos", en Última década, No. 7, Santiago de Chile, agosto de 1997, pp. 9-31.

\section{Publicaciones en internet}

LINDO-FUENTES, Héctor. "Anti-imperialismo salvadoreño, versión 1914", en El Faro Académico, 13 de enero de 2014, http://www.elfaro.net/es/201401/ academico/14446/. Consultado (15/02/2014).

\section{Tesis}

CAMPOS LARA, Óscar, "Cafetaleros de Santiago de María: la formación de un poder microregional en la Sierra Tecapa de Usulután, 1874-1917”, Tesis de licenciatura, Universidad Tecnológica de El Salvador, 2007.

GONZÁLEZ MÁRQUEZ, Luis Rubén. "Sociabilidad y organizaciones artesanalesobreras. La Sociedad de Artesanos El Porvenir de Santa Tecla, 1902-1932”. Tesis de licenciatura, Universidad de El Salvador, 2012.

LÓPEZ BERNAL, Carlos Gregorio, "Poder central y poder local en la construcción del Estado en El Salvador, 1840-1890", Tesis doctoral, Universidad de Costa Rica, 2007. 